\title{
Title: Aerosolized TLR Agonists Suppress Acute Sendai Virus Lung Infection and Chronic Airway Disease in Mice
}

Authors: David L. Goldblatt ${ }^{1 \dagger}$, Jose R. Flores ${ }^{1 \dagger}$, Gabriella Valverde $\mathrm{Ha}^{1 \dagger}$, Ana M. Jaramillo ${ }^{1}$, Sofya Tkachman ${ }^{1}$, Carson T. Kirkpatrick ${ }^{1}$, Shradha Wali ${ }^{1}$, Belinda Hernandez ${ }^{1}$, David E. Ost ${ }^{1}$, Brenton L. Scott ${ }^{2}$, Jichao Chen ${ }^{1}$, Scott E. Evans ${ }^{1}$, Michael J. Tuvim ${ }^{1}$, Burton F. Dickey ${ }^{1 *}$

\begin{abstract}
Affiliations:
${ }^{1}$ Department of Pulmonary Medicine, The University of Texas MD Anderson Cancer Center, Houston, Texas, 77030, USA.

${ }^{2}$ Pulmotect, Inc., 3900 Essex Lane, Houston, Texas, 77027, USA.

*To whom correspondence should be addressed. Email: dgoldblatt@ mdanderson.org; Phone: 609-304-4644; Fax: 713-563-0411. Or, Email: bdickey@ mdanderson.org. Phone: 713-563-4253; Fax: 713-794-4922.

${ }^{\dagger}$ These authors contributed equally to this work.

One Sentence Summary: Respiratory viral infections can induce chronic airway disease, and we find that stimulating innate immunity within the lungs of mice reduces the severity of acute infection and development of a chronic asthma phenotype.
\end{abstract}

Abstract: Respiratory viral infections play central roles in the initiation, exacerbation and progression of asthma in humans. An acute paramyxoviral infection in mice can cause a chronic lung disease that resembles human asthma. We sought to determine whether reduction of Sendai virus lung burden in mice by stimulating innate immunity with aerosolized Toll-like receptor (TLR) agonists could attenuate the severity of chronic asthma-like lung disease. Treatment with $1 \mu \mathrm{M}$ oligodeoxynucleotide (ODN) M362, an agonist of the TLR9 homodimer, and $4 \mu \mathrm{M}$ Pam2CSK4 (Pam2), an agonist of the TLR2/6 heterodimer, within a few days before or after Sendai virus challenge, resulted in a $\sim 75 \%$ reduction in lung Sendai virus burden five days after challenge. The reduction in acute lung virus burden was associated with marked reductions 49 days after viral challenge in eosinophilic and lymphocytic lung inflammation, airway mucous 
metaplasia, lumenal mucus occlusion, and hyperresponsiveness to methacholine.

Mechanistically, ODN/Pam2 treatment attenuated the chronic asthma phenotype by suppressing IL-33 production by type 2 pneumocytes, both by reducing the severity of acute infection and by downregulating Type 2 (allergic) inflammation. These data suggest that treatment of susceptible human hosts with aerosolized ODN and Pam2 at the time of a respiratory viral infection might attenuate the severity of the acute infection and reduce progression of asthma.

\section{Introduction}

Respiratory viral infections play a major role in the pathogenesis of asthma at every stage of disease - initiation, exacerbation, and progression (1-5). Regarding asthma initiation, children who experience a respiratory infection with rhinovirus or respiratory syncytial virus have a substantially increased chance of subsequently developing asthma. Regarding asthma exacerbations, new molecular techniques have allowed the identification of viral infections in more than $80 \%$ of exacerbation episodes in both children and adults. Last, progression of underlying asthma severity, defined as poorly reversible airflow obstruction and persistent symptoms, is associated with the frequency of respiratory viral infections. Rhinoviruses are the most common cause of asthma exacerbations, but paramyxoviruses such as respiratory syncytial virus and parainfluenza virus often cause severe disease and have a prominent role in disease initiation $(1,5)$.

While the epidemiologic association between respiratory virus infection and asthma is strong, a mechanistic explanation of the interaction has been lacking until recently. It now appears that the interaction operates in both directions. The presence of asthma results in an increased susceptibility to lower respiratory tract infection by viruses, possibly due at least in part to deficient interferon responses resulting from Type 2 immune deviation (2-4, 6, 7). Conversely, 
respiratory viral infection can result in long-term reprogramming of the lung immune environment towards a Type 2 polarity that results in parenchymal changes characteristic of asthma and COPD $(2-4,7,8)$. The greatest source of mechanistic insight in this regard has come from studies of a mouse paramyxoviral lung infection with Sendai virus (SeV) by Holtzman and colleagues $(9,10)$. Analysis of this model has revealed that an acute $\mathrm{SeV}$ infection, in which virus is cleared within 12 days, can lead to a chronic, possibly lifetime, asthmatic phenotype. In susceptible mouse strains, the lungs 49 days after infectious challenge are characterized by Type 2 inflammation, epithelial mucous metaplasia, and hyperresponsiveness to bronchoconstrictor stimuli such as methacholine $(6,8-10)$. In recent work, this group has shown that the acute $\mathrm{SeV}$ infection leads to long-term elevated expression of IL-33 by lung epithelial cells that drives the persistent elaboration of high levels of IL-13 by immune cells within the lungs, which in turn induces the lung parenchymal changes of epithelial mucous metaplasia and smooth muscle hyperresponsiveness (11).

In view of the high incidence and substantial morbidity resulting from virus-induced asthma, treatments to mitigate the severity of respiratory virus infection are greatly needed. We have previously identified a pharmacologic means to stimulate innate immunity of lung epithelium that has shown activity against multiple bacterial, fungal, and viral pathogens in mice (12-18) and guinea pigs (19). The stimulus consists of a class $\mathrm{C}$ oligodeoxynucleotide that is an agonist of the TLR9 homodimer and Pam2CSK4 that is an agonist of the TLR2/6 heterodimer. Administration of these two agonists (hereafter called O/P) in a fixed molar ratio shows synergistic activity against microbial pathogens that is dependent upon MyD88 expression in lung epithelial cells and the generation of microbicidal reactive oxygen species $(12,14,20,21)$. We hypothesized that treatment with $\mathrm{O} / \mathrm{P}$ at the time of respiratory infection with $\mathrm{SeV}$ would 
reduce lung virus burden during the acute infection and thereby attenuate the development of a late asthma phenotype.

\section{Results}

O/P treatment before SeV challenge reduces lung virus burden

The experimental paradigm is illustrated in Figure 1A. To test the first component of our hypothesis, mice were treated with aerosolized $\mathrm{O} / \mathrm{P}$ one day before challenge with $\mathrm{SeV}$ because previous studies showed this is the interval of maximal benefit of a single $\mathrm{O} / \mathrm{P}$ treatment for challenge with influenza virus or any of several bacterial pathogens (12-14). Lung SeV load was measured by RT-qPCR 5 days after challenge based upon this being the time of maximal viral burden in prior studies by others $(9,10,22,23)$ and our confirmatory study (fig. S1). Treatment with $\mathrm{O} / \mathrm{P}$ resulted in a 70-80\% reduction in $\mathrm{SeV}$ burden (Fig. $1 \mathrm{~B}$ and fig. S1). Pilot studies titrating SeV challenge to mouse survival showed a steep dose-response relationship, with a 1.6fold increase in virus load resulting in a decrease in mouse survival from $80 \%$ to $20 \%$ (Fig. 1C). Based on this tight relationship between viral burden and outcome, we anticipated a substantial change in late asthma phenotype with treatment, so proceeded to test the second component of the central hypothesis.

\section{O/P treatment before SeV challenge attenuates late asthma phenotype}

Mice were treated with aerosolized $\mathrm{O} / \mathrm{P}$ one day before challenge with $\mathrm{SeV}$, and the severity of an asthma phenotype 49 days after viral challenge was measured. Treatment resulted in an $88 \%$ reduction in lung lavage eosinophil number, indicating the attenuation of persistent Type 2 lung inflammation, and an $86 \%$ reduction in lymphocyte number, suggesting a possible reduction in Th2 cells that sustain Type 2 lung inflammation (Fig. 2A-B). We next examined whether the 
reduction in Type 2 inflammation resulted in reduced effects on lung parenchymal cells. There was a $52 \%$ reduction in mucous metaplasia measured as airway epithelial mucin content (Fig. 2C-D), and a 53\% reduction in airway hyperresponsiveness (AHR) measured as lung resistance to inflation after $30 \mathrm{mg} / \mathrm{ml}$ methacholine (Fig. 2E-F). These results suggest a causal relationship between the reduction in virus load from $\mathrm{O} / \mathrm{P}$ treatment and the chronic asthma phenotype, so further evidence was sought by examining dose-response and time-response relationships.

\section{Parallel dose-response relationships between acute SeV burden and late asthma phenotype}

Our previous studies had shown that the combination of $1 \mu \mathrm{M}$ ODN and $4 \mu \mathrm{M}$ Pam2CSK4 in 4 $\mathrm{ml}(1 \mathrm{X} \mathrm{O} / \mathrm{P})$ is on the inflection of the upper plateau of the dose-response curves for airway epithelial activation as measured by cytokine release (15) and for antimicrobial resistance as measured by the survival of mice from a microbial challenge $(15,20)$. Now, we evaluated the responses to two halving doses of $\mathrm{O} / \mathrm{P}$ below the $1 \mathrm{X}$ dose to interrogate the steep portion of the dose-response curve, and to two doubling doses above the $1 \mathrm{X}$ dose to confirm that responses were saturated. Mice treated one day before $\mathrm{SeV}$ challenge showed dose-dependent reductions in lung virus burden 5 days after challenge (Fig. 3A), and in lung lavage eosinophil and lymphocyte numbers (Fig. 3B) and mucous metaplasia (Fig. 3C) 49 days after challenge.

The correlation among these dose-response relationships supports a mechanistic interaction between the reduction in acute viral lung burden by $\mathrm{O} / \mathrm{P}$ treatment and the attenuation of a late asthma phenotype. However, it is notable that the maximal effect of $\mathrm{O} / \mathrm{P}$ on lung virus burden appeared to be at the $1 / 2 \mathrm{X}$ dose, on lung lavage eosinophil and lymphocyte levels at the $1 \mathrm{X}$ dose, and on mucous metaplasia at the $2 \mathrm{X}$ dose. These small concentration-dependent differences among outcomes were consistent across multiple experiments, and suggest that small unmeasurable differences in lung virus burden at higher O/P concentrations (Fig. 3A) are 
sufficient to cause measurable differences in persistent lung inflammation (Fig. 3B), leading in turn to downstream effects on lung parenchymal phenotype (Fig. 3C). This interpretation is consistent with the steep dose-response relationship between lung virus burden and mouse mortality (Fig. 1C).

Time-response relationships between acute SeV burden and late asthma phenotypes

To test temporal relationships, mice were treated with a $1 \mathrm{X}$ dose of $\mathrm{O} / \mathrm{P}$ at varying intervals before and after challenge with $\mathrm{SeV}$. Our previous studies showed variable durations of protection depending upon the intensity of the infectious challenge, with benefit observed with a pretreatment interval as long as eight days before a bacterial challenge of mild intensity (12), but as short as three days before a challenge of severe intensity (24). For treatments given after challenge, we have found a great difference between bacterial and viral pathogens, with a therapeutic window of less than one day for bacterial pathogens $(12,24)$, but of several days for influenza virus $(13,21)$. Based on these prior observations, responses to O/P from 10 days before to 3 days after $\mathrm{SeV}$ challenge were evaluated. A reduction in virus burden was seen from 10 days before challenge to 1 day after challenge (Fig. 3D). Reductions in eosinophils and lymphocytes were observed at all time points (Fig. 3E), and for mucous metaplasia at all time points except 3 days after challenge (Fig. 3F). Overall, there was a trend towards greater effects with shorter intervals between treatment and challenge. Similar to the dose-response relationship, the timedependent effects of $\mathrm{O} / \mathrm{P}$ treatment on leukocyte numbers were greater than on SeV burden (Fig. $3 \mathrm{E}-\mathrm{F})$.

The efficacy of O/P given 10 days before $\mathrm{SeV}$ challenge in these studies was surprising. To test whether $\mathrm{O} / \mathrm{P}$ might be influencing the development of a chronic asthma phenotype in the $\mathrm{SeV}$ infection model by exerting an immunomodulatory effect, $\mathrm{O} / \mathrm{P}$ was administered at time points 
substantially outside its known window of antimicrobial efficacy. Treatment with O/P 20 days before $\mathrm{SeV}$ challenge resulted in a reduction 49 days after challenge in eosinophils by $85 \%$ and lymphocytes by $75 \%$; similarly, treatment 20 days after $\mathrm{SeV}$ challenge resulted in a reduction 49 days after challenge in eosinophils by $73 \%$ and lymphocytes by $74 \%$ (fig. S2). These findings indicate that $\mathrm{O} / \mathrm{P}$ treatment attenuates the late asthma phenotype in $\mathrm{SeV}$-challenged mice by a combination of a reduction in acute lung virus burden and long-term immunomodulation away from a T2 lung inflammatory milieu.

\section{O/P treatment reduces airway mucus occlusion and acidophilic pneumonitis}

We observed multiple yellow nodules on the surface of the lungs of untreated mice challenged with $\mathrm{SeV} 49$ days earlier (Fig. 4A). Transillumination allowed us to enumerate nodules within the lungs (Fig. 4B), and to measure their mean diameter at $1.1 \mathrm{~mm}(\mathrm{SEM}=45 \mu \mathrm{m}, \mathrm{N}=37)$. Mice treated with $\mathrm{O} / \mathrm{P}$ one day before $\mathrm{SeV}$ challenge had a $92 \%$ reduction in nodule number (Fig. 4C). Histopathologic examination of the nodules showed alveolar accumulation of foamy macrophages, eosinophils, and Charcot-Leyden crystals (Fig. 4D-E), characteristic of “acidophilic pneumonitis" $(25,26)$. The identity of the macrophages was confirmed by immunofluorescence staining for CD68 (fig. S3D), and Sudan black staining showed the macrophages to be heavily laden with lipids (Fig. 4F), even more so than the normal staining of lamellar bodies in alveolar T2 cells (fig. S3E).

We hypothesized that mucus plugs caused airway obstruction leading to lipid-laden macrophage accumulation in alveoli. To evaluate this, uninflated lungs were fixed with methacarn to minimize changes in mucus volume and position, and then stained with PAFS to visualize mucins (27). Supporting this hypothesis, widespread mucus plugs were visible in the airways of mice challenged 49 days earlier with $\mathrm{SeV}$ (Fig. 4G, arrow), and were greatly reduced in the 
airways of mice treated with $\mathrm{O} / \mathrm{P}$ one day before challenge (Fig. 4H). The mucus plugs were contiguous with areas of intense airway epithelial mucous metaplasia (Fig. 4G, filled arrowhead), and the plugs contained both Muc5ac and Muc5b (fig. S3A-B). In the process of measuring airway lumenal mucus using a precision lung-slicing tool (fig. S4), we observed that lungs from untreated SeV-challenged mice were larger (25-30\% greater rostral-caudal length) than those from unchallenged or treated and challenged mice, consistent with the obstructive hyperinflation observed at autopsy in the lungs of human subjects who die from asthma (28).

Red PAFS staining also extended into alveolar regions distal to mucus plugs (Fig. 4H, open arrowhead), and these areas were also positive for Muc5ac and Muc5b immunohistochemical staining (fig. S3A), with relatively more Muc5ac staining in airways and relatively more Muc5b staining in alveolar regions. To assess whether mucus in alveolar regions might be due to local mucin production resulting from bronchiolization of alveolar epithelium, we stained for CCSP and acetylated tubulin, markers of airway secretory and ciliated cells, respectively. This showed normal staining in conducting airways as well as abnormal staining in alveolar regions (Fig. 4I$\mathrm{J})$.

\section{O/P treatment attenuates the disruption of epithelial mosaicism}

We considered that a possible additional contributor to airway lumenal mucus accumulation besides mucin hyperproduction might be impaired ciliary clearance because we and others have observed extensive epithelial cell death in the first 2 weeks after $\mathrm{SeV}$ challenge $(21,23,29-31)$. The airway epithelium was examined 2-7 weeks after SeV challenge by whole mount immunofluorescence microscopy, and the normal mosaic of secretory and ciliated cells was altered in multiple ways. Secretory cells, marked by CCSP staining, became more prominent than ciliated cells, marked by acetylated tubulin staining (Fig. 5 and fig. S5). This prominence 
was due to a modest increase in secretory cell number (fig. S5B) and a more substantial increase in secretory cell size and intensity of CCSP staining (Fig. 5 and fig. S5A). The increase in secretory cell size is likely due to distension by intracellular mucin content (Fig. 2C and 4G, and fig. S3A-B and S5C), as we have shown previously during mucous metaplasia $(32,33)$. The increase in intensity of CCSP staining (Fig. 5 and fig. S5A) likely reflects a combination of increased expression and redistribution from small apical secretory granules in naïve cells into large mucin-containing granules during Type 2 inflammation $(32,33)$. Besides these changes in cell proportions and size, an alteration of the normal epithelial polygonal mosaic was revealed by staining cell boundaries using antibodies to E-cadherin (Fig. 5), with cells taking on more elongated shapes and occurring in abnormally large clusters of secretory cells. We observed these changes as early as 2 weeks after $\mathrm{SeV}$ challenge (fig. S5), found they partially persisted partially through 7 weeks (not shown), and that there was a trend towards improvement by pretreatment with $\mathrm{O} / \mathrm{P}$ (fig. S5B).

\section{O/P treatment before SeV challenge reduces lung IL-33 expression 49 days later}

Holtzman and colleagues have shown that the effects of acute $\mathrm{SeV}$ infection are translated into a chronic asthma phenotype by persistently increased IL-33 expression in the lungs (11). Therefore we measured the effect of O/P treatment during acute $\mathrm{SeV}$ infection on IL-33 expression 49 days later. Naïve mice that were neither challenged with $\mathrm{SeV}$ nor treated with O/P showed scattered faint immunohistochemical staining for IL-33 in cells with the localization (corners of polygonal alveoli) and morphology (cuboidal and protruding into the alveolar lumen) of type 2 pneumocytes (Fig. 6A). This finding is consistent with reports of substantial expression of IL-33 in type 2 pneumocytes of healthy mice $(34,35)$. There was no apparent change in IL-33 expression in the lungs of unchallenged mice treated with $\mathrm{O} / \mathrm{P}$, but mice challenged with $\mathrm{SeV}$ 
and not treated with $\mathrm{O} / \mathrm{P}$ showed a dramatic increase in the intensity and frequency of IL-33 staining of type 2 pneumocytes and faint staining of macrophages (Fig. 6A). This was quantified by immunofluorescence staining (Fig. 6B), and mice treated with $\mathrm{O} / \mathrm{P}$ and then challenged one day later with $\mathrm{SeV}$ showed a marked reduction in IL-33 staining (Fig. 6A-B). Immunofluorescence co-localization of IL-33 staining with lineage markers showed that highlevel IL-33 expression in SeV-challenged mice occurred exclusively in type 2 pneumocytes, with 97\% of IL-33-positive cells also positive for pro-SP-C (Fig. 6C) and no measurable IL-33 staining in Krt14-positive basal cells of the conducting airways (Fig. 6D) or in CD68-positive alveolar macrophages (Fig. 6E) ( $\mathrm{n}=100$ cells in 3 mice for each lineage marker). In SeVchallenged mice, $71 \%$ of pro-SP-C-positive cells were positive for IL-33 staining ( $\mathrm{n}=100$ cells in 3 mice).

Multiple doses of $\mathrm{O} / \mathrm{P}$ neither induce tachyphylaxis nor augment efficacy

We next sought to determine whether multiple O/P doses induce tachyphylaxis or improve outcomes. Repetitive treatment with 2 to 4 doses of O/P given daily or separated by 2 or 3 days between doses, with the final dose for each regimen given one day before $\mathrm{SeV}$ challenge (Fig. 7A), did not result in any measurable differences in the reduction of lung viral burden by O/P compared to a single treatment (Fig. 7B). Therefore we concluded that there is no tachyphylaxis of the antiviral effect of $\mathrm{O} / \mathrm{P}$ treatment, similar to what we have previously observed with influenza virus and bacterial pathogens $(36,37)$, so we proceeded to test whether multiple dosing improved outcomes.

Treatment with $\mathrm{O} / \mathrm{P}$ both one day before and one day after $\mathrm{SeV}$ challenge did not reduce lung virus burden more than a single treatment before challenge (Fig. 7C). Similarly, when late asthma outcomes were examined, treatment both before and after challenge was no more 
effective than a single treatment before challenge in reducing lung lavage eosinophils and lymphocytes (Fig. 7D) or epithelial mucin content (Fig. 7E). In each case, treatment one day after challenge was less effective than treatment one day after challenge (Fig. 7C-E).

\section{Comparison of O/P to IFN- $\beta$ effects on lung SeV burden and asthma phenotype}

IFN- $\beta$ has been shown to be a key signaling molecule in defense against respiratory viral infections, and aerosolized IFN- $\beta$ has progressed to clinical trials for the treatment of virusinduced asthma exacerbations (38). To compare treatment with $\mathrm{O} / \mathrm{P}$ to IFN- $\beta$, we first developed an IFN- $\beta$ treatment paradigm in mice. Serum CXCL10 levels were used as a biomarker of antiviral activity in the published clinical trial (38), so we measured CXCL10 levels in BALF in mouse pilot studies. The time of peak CXCL10 level in BALF was $2 \mathrm{~h}$ after aerosolized IFN- $\beta$ treatment (fig. S6A), and a dose of 400,000 IFN- $\beta$ units resulted in a CXCL10 level that lay on the edge of the upper plateau of the dose-response curve (fig. S6B), so this treatment timing and dose was used in efficacy studies. Reductions in lung SeV burden acutely (Fig. 8A), and in lavage eosinophils and lymphocytes (Fig. 8B) and in epithelial mucin content (Fig. 8C) 49 days after $\mathrm{SeV}$ challenge, were similar between $\mathrm{O} / \mathrm{P}$ and IFN- $\beta$ treatments.

$\mathrm{O} / \mathrm{P}$ treatment does not cause a rise in Type I interferons $(12-14,21)$, so we wondered whether $\mathrm{O} / \mathrm{P}$ and IFN- $\beta$ might have an additive effect. Supporting separate mechanisms of action, pilot studies showed that treatment with $\mathrm{O} / \mathrm{P}$ or IFN- $\beta$ elicited different cytokine profiles, with $\mathrm{O} / \mathrm{P}$ causing a substantially greater rise in CXCL2 and TNF- $\alpha$, and IFN- $\beta$ causing a greater rise in CXCL10 (fig. S6C). In addition, both treatments together caused a synergistic rise in IL-6 (fig. S6C). Despite these promising preliminary data, there was no apparent benefit to treating mice with both drugs simultaneously on lung SeV burden, lavage eosinophils and lymphocytes, or epithelial mucin content (Fig. 8A-C). To further test the possibility of additive activity of the two 
drugs, we gave a high-intensity $\mathrm{SeV}$ challenge $\left(2.5 \times \mathrm{LD}_{50}\right)$, for which there was no apparent reduction in lung $\mathrm{SeV}$ burden by either drug alone (Fig. 8D). However, the combination of both drugs reduced lung SeV burden significantly compared to the absence of treatment or to treatment with either drug along (Fig. 8D).

\section{Discussion}

Recent advances in molecular diagnostics have strengthened the tight association between viral infection and asthma initiation, exacerbation, and progression (1-4). Complementing this data, recent work with animal models has supported a causal role of respiratory viral infections in promoting long-term asthma-like disease and has enabled the identification of critical pathways in translating acute infection into chronic disease $(5,6,11,19,30,39)$. Together, these developments highlight the importance of attenuating the severity of respiratory viral infections to prevent chronic airway diseases. We have previously identified a means of effectively stimulating the airway epithelium to induce innate immune resistance to respiratory viral infection (12-21). Here we show that treatment of mice with this efficacious combination of aerosolized TLR ligands around the time of $\mathrm{SeV}$ infection attenuates chronic lung disease, providing proof-of-principle that this intervention might have clinical efficacy.

Based upon our prior studies showing that treatment with $\mathrm{O} / \mathrm{P}$ results in rapid pathogen killing within the lungs, we hypothesized that the major mechanism of action of $\mathrm{O} / \mathrm{P}$ in ameliorating chronic SeV-induced lung disease would be by reducing lung virus burden. The close doseresponse relationship between acute $\mathrm{SeV}$ lung burden and chronic asthma phenotypes supports such a causal relationship (Fig. 3A-C). The relationship between SeV lung burden and acute disease is steep, with a 1.6-fold decrease in viral burden resulting in a 4-fold decrease in mouse death (Fig. 1C). Similarly, reduction of SeV lung burden by $70-80 \%$ has a dramatic effect on 
chronic disease (Fig. 1B, 3A, 3D, 7B-C, 8A). This contrasts with the need for multiple log reductions in pathogen burden in chronic mycobacterial lung infection and acute bacterial blood infections to achieve comparable benefit, reflecting the capability of small numbers of residual organisms to perpetuate disease or develop drug resistance in those infections.

The major mechanism of pathogen killing with $\mathrm{O} / \mathrm{P}$ treatment is the activation of reactive oxygen generators in airway epithelial cells, which persists at a high level for several days, then slowly declines to its baseline level $(14,18,21)$. This is consistent with the reduction in SeV lung burden when mice are treated in the few days before or after challenge (Fig. 1D). However, the substantial reduction in lung inflammation 49 days after $\mathrm{SeV}$ challenge observed in mice treated 10 days before challenge with $\mathrm{O} / \mathrm{P}$ (Fig. 3E), when there is not a significant effect on lung viral burden in this (Fig. 3D) or our previous studies $(13,21)$, suggested an additional effect besides viral killing. To further explore this, we treated mice with $\mathrm{O} / \mathrm{P}$ either 20 days before or 20 days after $\mathrm{SeV}$ challenge and observed substantial effects on lung inflammation 49 days after $\mathrm{SeV}$ challenge (fig. S2). This suggests that $\mathrm{O} / \mathrm{P}$ also exerts an immunomodulatory effect on lung epithelium that additionally attenuates the chronic inflammatory lung phenotype independent of its antiviral effect. Holtzman and colleagues have shown that persistent expression of high levels of IL-33 in the lungs of SeV-challenged mice connects the acute infection to the chronic disease (11). Consistent with this, O/P treatment markedly reduced IL-33 expression in alveolar T2 cells (Fig. 6), which are thought to signal to distal airways in an "outside-in" manner $(34,35,40,41)$. The degree to which the reduction in IL-33 expression by O/P treatment reflects decreased epithelial cell injury and death and the degree to which it reflects immune modulation will require further study. 
A prominent feature of chronic lung disease in $\mathrm{SeV}$-challenged mice was the presence of multiple millimeter-sized nodules (Fig. 4A-C). By microscopic analysis, these were comprised of areas of acidophilic pneumonitis $(25,26)$, characterized by lipid-laden foamy macrophages, eosinophilic and lymphocytic inflammation, and Charcot-Leyden crystals (Fig. 4D-F), as well as areas of bronchiolization characterized by alveolar regions replaced by nests of club and ciliated cells (Fig. 4I-J). Abundant mucus was observed occluding airway lumens and also in alveolar regions (Fig. 4G and fig. S3). Airway mucus occlusion was likely due primarily to high levels of mucin production and secretion (Fig. 2C-D, Fig. 3C and 3F, Fig. 4G, and fig. S3A-B), but epithelial destruction during the first two weeks after infection, as observed previously (23, 30, 31), with a failure to restore a normal mucociliary epithelial mosaic during the following five weeks (Fig. 5 and fig. S5) probably contributed as well. Other possible mechanisms contributing to airway mucus occlusion might include airway surface liquid depletion due to inflammation during viral infection that has been observed by others but was not examined here (42). The presence of mucus in alveolar regions (Fig. 4G and fig. S3A) was more likely due to mucin synthesis and secretion by bronchiolized epithelium than by reflux from the conducting airways because of the tapering anatomy of airways and inability of terminal bronchioles to produce mucin $(32,43)$, the presence of intraepithelial mucin in bronchiolized alveolar epithelium indicating local production (fig. S3A), and the greater abundance of Muc5b relative to Muc5ac in alveolar regions compared to conducting airways suggesting different sources of mucus (fig. S3A). Both the number of macroscopic lung nodules (Fig. 4B) and the extent of airway mucus occlusion (Fig. 4H) were markedly reduced by treatment with O/P.

Our study has several limitations in predicting whether $\mathrm{O} / \mathrm{P}$ will be an effective therapeutic agent in humans. These include the inherent differences between mice and humans in anatomy, 
molecular biology, and interactions with pathogens. Offsetting this limitation, $\mathrm{SeV}$ is a paramyxovirus closely related to respiratory syncytial virus and parainfluenza viruses that cause considerable respiratory disease in humans, and $\mathrm{SeV}$ is a natural pathogen of rodents that replicates in their lungs and causes injury resembling that of human paramyxoviral infections (6, $8,11,23,30,31)$. In addition, the efficacy of $\mathrm{O} / \mathrm{P}$ in inducing epithelial resistance to viral infection in human airway cells has been demonstrated in vitro (21). Another limitation is that $\mathrm{SeV}$ infection of the lungs was induced in mice by bolus aspiration, whereas human infection most commonly proceeds by inhalation of small infected droplets from the upper respiratory tract. However, this should mostly affect the timing of treatment, which can be determined empirically in human subjects, rather than the underlying therapeutic principle.

Treatment of susceptible human subjects with $\mathrm{O} / \mathrm{P}$ has the potential to prevent the substantial morbidity associated with respiratory viruses in the pathogenesis of airway diseases including asthma, COPD, and cystic fibrosis. We have treated 49 normal human subjects in a single-dose, ascending, dose-strength trial (NCT02124278), and a multiple-dose safety and tolerability trial (NCT02566252). Treatment was well tolerated, and we believe we reached the upper plateau of the dose-response curve based upon small rises in blood neutrophils and C-reactive protein levels resembling the small sigmoidal-shaped plots of rises in blood IL-6 levels in mice (15). Next steps in development of the drug include viral challenge studies in subjects with airway disease (4446), followed by natural infection preemption studies in subjects with airway disease or immune compromise $(20,38,47,48)$. O/P showed reductions in acute $\mathrm{SeV}$ lung burden and chronic asthma phenotypes comparable to those seen with aerosolized IFN- $\beta$ in mice (Fig. 8), and in a clinical trial, IFN- $\beta$ administered within 24 hours of the onset of cold symptoms reduced asthma symptoms and the fall in peak expiratory flow in difficult-to-treat asthmatics (38). Together, O/P 
and IFN- $\beta$ show additive or synergistic activity in mice (Fig. 8D and fig. S6C), which is not surprising in view of their differing mechanisms of action with $\mathrm{O} / \mathrm{P}$ causing no induction of Type I interferons $(12-14,21)$. Whether either or both of these drugs, or some other stimulant of innate epithelial resistance to infection, can ameliorate the burden of virus-caused airway disease will be determined in future clinical trials of efficacy and safety.

\section{Materials and Methods}

\section{Mice and chemicals}

Seven week-old female C57BL/6J mice were obtained from the Jackson Laboratory (Sacramento, CA) and housed in specific pathogen-free conditions on a 12-hour light/dark cycle with free access to food and water. For euthanasia, mice were injected intraperitoneally with 2,2,2-tribromoethanol $(250 \mathrm{mg} / \mathrm{kg})$ and exsanguinated by transection of the abdominal aorta. All procedures were performed in accordance with the Institutional Animal Care and Use Committee of MD Anderson Cancer Center and the Texas A\&M Institute for Biosciences and Technology. Chemicals were obtained from MilliporeSigma (St. Louis, MO) unless otherwise specified.

\section{Viral challenge}

Sendai virus (parainfluenza type 1) was obtained from the ATCC (Manassas, VA) and expanded in primary rhesus monkey kidney cells obtained from Cell Pro Labs (Golden Valley, MN). In most experiments, mice were infected with $2.4 \times 10^{6}$ plaque forming units (pfu) in $40 \mu 1 \mathrm{PBS}$ instilled into the oropharynx and aspirated into the lungs, with mice suspended by the upper incisors on a board at $60^{\circ}$ from horizontal under isoflurane inhalation anesthesia. The dose of virus was chosen to result in severe bronchopneumonia, but with death in $<20 \%$ of mice. Lower and higher concentrations of $\mathrm{SeV}$ were given in pilot experiments to establish an optimal dose 
for chronic studies (Fig. 1C), and in a high-dose challenge study $\left(1.2 \times 10^{8} \mathrm{pfu}\right)$ to examine additive effects of $\mathrm{O} / \mathrm{P}$ and IFN- $\beta$ (Fig. 8D). Lung virus burden was measured by reverse transcription quantitative PCR (RT-qPCR) of the Sendai matrix (M) protein normalized to mouse 18S rRNA as described (39), except for substitution of the primers to ACTGGGACCCTATCTAAGACAT and TAGTAGCGGAAATCACGAGG, and analyzed by the comparative $\mathrm{C}_{\mathrm{T}}$ method (49).

\section{Treatment with aerosolized $O / P$}

This was performed as described (15). Briefly, ODN 5' TCG TCG TCG TTC GAA CGA CGT TGA T 3' as the sodium salt on a phosphorothioate backbone (ODN M362) was purchased from TriLink BioTechnologies (San Diego, CA), and 2,3-bis(palmitoyloxy)-2-propyl-Cys-Ser-LysLys-Lys-Lys-OH (Pam2CSK4) as the trifluoroacetic acid salt was purchased from Peptides International (Louisville, KY). A solution of ODN (1 $\mu \mathrm{M})$ and Pam2CSK4 (4 $\mu \mathrm{M})$ in endotoxinfree sterile water $(8 \mathrm{ml})$ was placed in an Aerotech II nebulizer (Biodex Medical Systems, Shirley, NY) driven by $10 \mathrm{l} / \mathrm{min}$ of $5 \% \mathrm{CO}_{2}$ in air to promote deep breathing. The nebulizer was connected by polyethylene tubing $(30 \mathrm{~cm} \times 22 \mathrm{~mm})$ to a 101 polyethylene chamber vented to a biosafety hood. Mice were exposed to the aerosol for $20 \mathrm{~min}$, resulting in the nebulization of $\sim 4$ $\mathrm{ml}$ of $\mathrm{O} / \mathrm{P}$ solution. In one set of experiments determining dose-response relationships, the concentration of $\mathrm{O} / \mathrm{P}$ solution was varied as indicated.

\section{Lung lavage}

This was performed by instilling and collecting two $1 \mathrm{ml}$ aliquots of PBS through a 20 gauge cannula inserted through rings of the exposed trachea of euthanized animals, then combining the aliquots as described (15). Total leukocyte count was determined using a hemocytometer, and 
differential counts by cytocentrifugation of $200 \mu \mathrm{l}$ of lavage fluid at $300 \mathrm{~g}$ for $5 \mathrm{~min}$ followed by Wright-Giemsa staining.

\section{Epithelial mucin content and lumenal mucus occlusion}

Epithelial mucin content was measured as described $(32,50,51)$. Briefly, lungs were fixed by intratracheal inflation with $10 \%$ formalin to $20 \mathrm{~cm} \mathrm{H}_{2} \mathrm{O}$ pressure for $12 \mathrm{~h}$, and then embedded in paraffin. Tissue blocks were cut into 5- $\mu$ m sections, mounted on frosted glass slides (Medline, Northfield, IL), deparaffinized with xylene, washed with ethanol, then rehydrated and stained with periodic acid fluorescent Schiff reagent (PAFS). Images were acquired by investigators blinded to mouse treatment, and morphometric analysis of the images for quantitation of intracellular mucin was performed using ImagePro (Media Cybernetics, Bethesda, MD). Data are presented as epithelial mucin volume density, signifying the measured volume of mucin overlying a unit area of epithelial basal lamina. Airway mucus plugging was measured by modifications, as follows, of a method we have described previously (52). Lungs were fixed by immersion, to avoid displacement of lumenal mucus by inflation, in methanol-based Carnoy's solution (methacarn), to minimize changes in mucus volume, for $48 \mathrm{~h}$ at $4^{\circ} \mathrm{C}$. Lungs were then excised, and the left lung was placed in a precision cutting tool to generate $1 \mathrm{~mm}$ transverse slices (fig. S3D). Four slices were embedded in paraffin, with two slices taken below the hilum and two above, each separated by a $1 \mathrm{~mm}$ slice that was discarded. One $5 \mu \mathrm{m}$ section was taken from each slice, deparaffinized, rehydrated, and then stained with PAFS. The total area of lumenal mucus in all 4 slices was measured for each lung using ImageJ software (53).

\section{Lung mechanics}

These were analyzed using a flexiVent (Scireq, Montreal, Canada) forced oscillation ventilator system as described (54). Briefly, mice were anaesthetized with urethane (2 mg/g i.p.) and 
paralyzed with succinylcholine chloride $(500 \mu \mathrm{g}$ i.p. followed by continuous i.p. infusion at 10 $\mu \mathrm{g} / \mathrm{g} \cdot \mathrm{min})$. They were then tracheostomized and ventilated at $150 \mathrm{breaths} / \mathrm{min}, 10 \mu \mathrm{l} / \mathrm{g}$, against 2$3 \mathrm{~cm} \mathrm{H}_{2} \mathrm{O}$ positive end-expiratory pressure. Respiratory resistance was assessed at baseline and in response to three incremental doses of aerosolized methacholine (MCh) $(3,10$ and $30 \mathrm{mg} / \mathrm{ml})$ administered by an in-line ultrasonic nebulizer (4-6 $\mu \mathrm{m}$, Aerogen, Ireland). Total respiratory resistance was calculated by averaging five values measured for each dose of MCh for each mouse.

\section{Histochemistry}

Cellular elements and tissue morphology were examined with hematoxylin and eosin (H\&E) staining, and collagen and lipids in nodules were visualized with picrosirius red (PSR) and Sudan black B staining, respectively. For H\&E and PSR staining, lungs were fixed and sectioned as above. For H\&E staining, slides were incubated in Harris' hematoxylin, eosin and graded ethanol. For PSR staining, slides were incubated in direct red 80 with picric acid for $1 \mathrm{~h}$, then rinsed with acidified water. To image lipids, fixed lungs were cut into lobes and immersed in 10\% Optimal Cutting Temperature compound (Tissue-Tek OCT; Sakura, Torrance, CA) and $20 \%$ sucrose in PBS on a rocker at $4^{\circ} \mathrm{C}$ overnight. Tissue was then frozen in OCT, cut into 10$\mu \mathrm{m}$ sections, and mounted on Superfrost Plus glass slides (Fisher Scientific, Hampton, NH) for this and all other studies using frozen tissue. Sections were stained with Sudan black B (Rowley Biochemical, Danvers, MA) for $1 \mathrm{~h}$ and counterstained with Kernechtrot's nuclear fast red (Rowley) for 20 min, followed by mounting with AquaMount medium (Polysciences, Warrington, PA). All images were acquired with an Olympus BX 60 microscope at 10x or 40x objectives unless otherwise specified. 


\section{Immunohistochemistry}

Mouse lungs were fixed, embedded, sectioned, and deparaffinized as above, then exposed for 10 min to $3 \% \mathrm{H}_{2} \mathrm{O}_{2}$ in $90 \%$ methanol, and then heated for $10 \mathrm{~min}$ in $10 \mathrm{mM}$ sodium citrate, $\mathrm{pH}$ 6.0, for antigen retrieval. Slides were rinsed in water, blocked in horse serum (Vector Laboratories, Burlingame, CA) or goat serum (Jackson ImmunoResearch, West Grove, PA) for 1h, then rinsed again and incubated with primary antibodies diluted in blocking solution at $4^{\circ} \mathrm{C}$ overnight. Primary antibodies used were: goat anti-mouse IL-33 (AF3626, R\&D Systems, Minneapolis, MN; 1:1000), rabbit anti-Muc5ac (gift from Dr. Camille Ehre, 1:500) (55), and mouse monoclonal antibody MDA-3E1 (1:500) to detect Muc5b (54). After incubation, secondary antibodies - biotinylated horse anti-goat IgG (Vector), horseradish peroxidase (HRP)-labelled goat anti-rabbit (Millipore-Sigma) or HRP-labelled goat anti-mouse antibody (ThermoFisher Scientific) - were added for $2 \mathrm{~h}$ at room temperature. Tissue sections were then washed with PBS, counterstained with H\&E, and mounted with VectaMount (Vector).

\section{Immunofluorescence}

Lungs were frozen in OCT and cut into $10-\mu \mathrm{m}$ sections as above. Sections mounted on glass slides were thawed, washed with water, blocked with donkey serum (Jackson ImmunoResearch), then incubated with primary antibodies overnight at $4^{\circ} \mathrm{C}$. Primary antibodies used were: rabbit anti-prosurfactant protein C (AB3786, EMD Millipore, Burlington, MA; 1:1000), rabbit antikeratin 14 (KRT14, RB-9020-P0, Thermo Fisher, Waltham, MA; 1:500), rat anti-mouse CD68 (FA-11, BioLegend, San Diego; 1:200), and anti-Muc5ac and anti-Muc5b as above. This was followed by the addition of secondary antibodies conjugated to Alexa 555 (Cy3), Alexa 488 (FITC) and DAPI (Jackson ImmunoResearch) for $2 \mathrm{~h}$. A confocal microscope (A1plus, Nikon) was used to acquire all images. For quantitative studies, random images were acquired by 
investigators blinded to subject identity. Percentages of IL-33 positive cells were counted using ImageJ (Fig. 6C-E). To measure IL-33 fluorescence intensity (Fig. 6B), the left lung was sectioned at the axial bronchus between lateral branches 1 and 2 using a precision cutting tool (fig. S4), then imaged using an upright microscope (Olympus BX 60) with a 40x lens objective and identical parameters of exposure time, color intensity, contrast and magnification. Images were uploaded to ImageJ, and a red (IL-33) background intensity threshold was established by first measuring fluorescence intensity for background regions (those without blue nuclear staining) and regions of interest (double-positive red and blue staining). The threshold was then set as the mean between maximal background regions and mean regions of interest, and subtracted from all fields. The "Oval" tool was used to identify IL-33+ nuclei, these were imaged in grey scale (Fig. 6B inset), and grey scale values for all pixels in a field were plotted as arbitrary fluorescence intensity units (Fig. 6B).

\section{Whole mount immunofluorescence}

Fixed lung lobes were embedded in OCT as above, then frozen sections of 100 200 $\mu \mathrm{m}$ thickness were cut. Sections were thawed and blocked in $2 \mathrm{ml}$ Eppendorf tubes containing PBS with $0.3 \%$ TritonX-100 and 2.5\% donkey serum (017-000-121, Jackson ImmunoResearch) on a rocker at room temperature for $2 \mathrm{~h}$. After blocking, lung tissues were incubated with primary antibodies diluted in PBS with $0.3 \%$ TritonX-100 on a rocker at $4{ }^{\circ} \mathrm{C}$ overnight. Primary antibodies used (Fig. 5) were: rat anti-E-cadherin (E-Cad, 131900, Invitrogen; 1:1000), goat antiCCSP (1:2,500, a gift from Dr. Barry Stripp), and mouse anti-acetylated tubulin (Ac-Tub, T6793, MilliporeSigma; 1:2,000). On the second day, lung tissues were washed in PBS with 1\% TritonX-100 and 1\% Tween-20 for $3 \mathrm{~h}$, then incubated with secondary antibodies diluted in PBS with $0.3 \%$ Triton $\mathrm{X}-100$ on a rocker at $4{ }^{0} \mathrm{C}$ overnight. Fluorescent secondary antibodies were 
obtained from Jackson ImmunoResearch and used at 1:1,000. On the third day, lung tissues were again washed in PBS with 1\% TritonX-100 and 1\% Tween-20 for $3 \mathrm{~h}$, washed with PBS twice for 5 min, fixed with $2 \%$ PFA for $2 \mathrm{~h}$ on a rocker, and washed with PBS for $1 \mathrm{~h}$. After the PBS wash, lung tissues were mounted with AquaMount and airways of the left main bronchi were imaged on a Nikon A1plus confocal microscope. For each lung, six image fields - each consisting of several hundred epithelial cells - were counted.

\section{Treatment with aerosolized IFN- $\beta$}

In time-course and dose-finding pilot studies, mice were treated with varying concentrations of aerosolized IFN- $\beta$ (R\&D Systems, Minneapolis, $\mathrm{MN}$ ) with $0.05 \%$ BSA in water $(8 \mathrm{ml})$ as described above for $\mathrm{O} / \mathrm{P}$, except that the aerosolization was continued until all IFN- $\beta$ was delivered (approximately $40 \mathrm{~min}$ ). At varying times after treatment, mice were euthanized and underwent bronchoalveolar lavage for measurement of cytokines. In efficacy studies, mice were treated with 400,000 units of aerosolized IFN- $\beta$, then challenged the next day with Sendai virus by oropharyngeal instillation and euthanized five days later for measure of lung virus burden.

\section{Statistical analyses}

All data sets were first analyzed with the Shapiro-Wilk test to determine normality. For analyses where there was only a single comparison between two groups, data was analyzed by Student's $t$ test or Mann-Whitney $U$ test for normally and non-normally distributed data, respectively. For analyses where multiple experimental groups were compared against a single control, data were first analyzed by ANOVA on ranks to determine if a significant difference between any groups was present. If found, data were further analyzed using Dunn's test and significance determined from adjusted $P$ values. For analyses where each experimental group was compared to every other group, data were first analyzed by one-way ANOVA or ANOVA on ranks for normally 
and non-normally distributed data, respectively. If a significant difference between any groups was present by ANOVA, data were further analyzed using Holm-Sidak's test for one-way ANOVA or Dunn's test for all pairwise combinations for ANOVA on ranks. Significance was determined from adjusted $P$ values. For studies comparing O/P and IFN- $\beta$, an interaction score from linear regression analysis was used to determine whether there was a synergistic effect of the combination compared to either drug alone. All data were analyzed using SigmaPlot (version 12.5, Systat Software). $P<0.05$ was considered statistically significant.

\section{Supplementary Materials}

Fig. S1. Lung SeV burden days 3 through 7 after infection.

Fig. S2. Effect of O/P treatment 20 days before or after SeV infection.

Fig. S3. Staining for Muc5ac and Muc5b, collagen, and macrophages in lung nodules.

Fig. S4. Location of left axial bronchus sections for mucin content, and image of the precision cutting instrument.

Fig. S5. Whole mount and cross-sectional immunofluorescence staining of airway epithelium 14 days after Sendai infection.

Fig. S6. Lung lavage fluid cytokine responses to aerosolized O/P and IFN- $\beta$.

Acknowledgements: The authors thank Mark McArthur, DVM, for helpful discussions of pathologic findings. Funding: NIH, NHLBI, R01 HL129795 to BFD, R44 HL115903 to BLS, and R01 HL117976, DP2 HL123229, and R35 HL144805 to SEE; Cystic Fibrosis Foundation grants Dickey15PO and Dickey18GO to BFD. Author contributions: BLS, SEE, MJT, BFD conceived the study; DLG, JRF, GV, AMJ, ST, SW, BH, JC performed the studies; DEO oversaw the statistical analyses; MJT made the figures; BFD wrote the manuscript. Competing 
interests: SEE, MJT and BFD are inventors on US patent 8,883,174 "Compositions for

Stimulation of Mammalian Innate Immune Resistance to Pathogens”, which has been licensed by their employer, the University of Texas MD Anderson Cancer Center, to Pulmotect, Inc., which is developing $\mathrm{O} / \mathrm{P}$ as a therapeutic for respiratory infections. In addition, BLS, SEE, MJT and BFD hold equity in Pulmotect, Inc., and BLS is employed by Pulmotect, Inc.

\section{References}

1. Busse WW, Lemanske RF, Jr., Gern JE. Role of viral respiratory infections in asthma and asthma exacerbations. Lancet. 2010;376(9743):826-34.

2. Farne HA, Johnston SL. Immune mechanisms of respiratory viral infections in asthma. Curr Opin Immunol. 2017;48:31-7.

3. Holt PG, Sly PD. Viral infections and atopy in asthma pathogenesis: new rationales for asthma prevention and treatment. Nat Med. 2012;18(5):726-35.

4. Holgate ST. Innate and adaptive immune responses in asthma. Nat Med. 2012;18(5):67383.

5. Peebles RS, Jr., Aronica MA. Proinflammatory Pathways in the Pathogenesis of Asthma. Clin Chest Med. 2019;40(1):29-50.

6. Holtzman MJ, Patel DA, Zhang Y, Patel AC. Host epithelial-viral interactions as cause and cure for asthma. Curr Opin Immunol. 2011;23(4):487-94.

7. Lambrecht BN, Hammad H. The immunology of asthma. Nat Immunol. 2015;16(1):4556.

8. Holtzman MJ. Asthma as a chronic disease of the innate and adaptive immune systems responding to viruses and allergens. J Clin Invest. 2012;122(8):2741-8.

9. Walter MJ, Morton JD, Kajiwara N, Agapov E, Holtzman MJ. Viral induction of a chronic asthma phenotype and genetic segregation from the acute response. J Clin Invest. 2002;110(2):165-75.

10. Patel AC, Morton JD, Kim EY, Alevy Y, Swanson S, Tucker J, et al. Genetic segregation of airway disease traits despite redundancy of calcium-activated chloride channel family members. Physiol Genomics. 2006;25(3):502-13.

11. Byers DE, Alexander-Brett J, Patel AC, Agapov E, Dang-Vu G, Jin X, et al. Long-term IL-33-producing epithelial progenitor cells in chronic obstructive lung disease. J Clin Invest. 2013;123(9):3967-82.

12. Duggan JM, You D, Cleaver JO, Larson DT, Garza RJ, Guzman Pruneda FA, et al. Synergistic interactions of TLR2/6 and TLR9 induce a high level of resistance to lung infection in mice. J Immunol. 2011;186(10):5916-26.

13. Tuvim MJ, Gilbert BE, Dickey BF, Evans SE. Synergistic TLR2/6 and TLR9 Activation Protects Mice against Lethal Influenza Pneumonia. PLoS ONE. 2012;7(1):e30596.

14. Cleaver JO, You D, Michaud DR, Pruneda FA, Juarez MM, Zhang J, et al. Lung epithelial cells are essential effectors of inducible resistance to pneumonia. Mucosal Immunol. 2014;7(1):78-88. 
15. Alfaro VY, Goldblatt DL, Valverde GR, Munsell MF, Quinton LJ, Walker AK, et al. Safety, tolerability, and biomarkers of the treatment of mice with aerosolized Toll-like receptor ligands. Front Pharmacol. 2014;5:8.

16. Leiva-Juarez MM, Ware HH, Kulkarni VV, Zweidler-McKay PA, Tuvim MJ, Evans SE. Inducible epithelial resistance protects mice against leukemia-associated pneumonia. Blood. 2016;128(7):982-92.

17. Leiva-Juarez MM, Kirkpatrick CT, Gilbert BE, Scott B, Tuvim MJ, Dickey BF, et al. Combined aerosolized Toll-like receptor ligands are an effective therapeutic agent against influenza pneumonia when co-administered with oseltamivir. Eur J Pharmacol. 2018;818:191-7. 18. Ware HH, Kulkarni VV, Wang Y, Pantaleon Garcia J, Leiva Juarez M, Kirkpatrick CT, et al. Inducible lung epithelial resistance requires multisource reactive oxygen species generation to protect against bacterial infections. PLoS One. 2019;14(2):e0208216.

19. Drake MG, Evans SE, Dickey BF, Fryer AD, Jacoby DB. TLR2/6 and TLR9 agonists suppress viral replication but not airway hyperreactivity in guinea pigs. Am J Respir Cell Mol Biol. 2013.

20. Evans SE, Tuvim MJ, Fox CJ, Sachdev N, Gibiansky L, Dickey BF. Inhaled innate immune ligands to prevent pneumonia. Br J Pharmacol. 2011;163(1):195-206.

21. Kirkpatrick CT, Wang Y, Leiva Juarez MM, Shivshankar P, Pantaleon Garcia J, Plumer AK, et al. Inducible Lung Epithelial Resistance Requires Multisource Reactive Oxygen Species Generation To Protect against Viral Infections. MBio. 2018;9(3).

22. Hines EA, Szakaly RJ, Leng N, Webster AT, Verheyden JM, Lashua AJ, et al. Comparison of temporal transcriptomic profiles from immature lungs of two rat strains reveals a viral response signature associated with chronic lung dysfunction. PLoS One.

2014;9(12):e112997.

23. Massion PP, Funari CC, Ueki I, Ikeda S, McDonald DM, Nadel JA. Parainfluenza (Sendai) virus infects ciliated cells and secretory cells but not basal cells of rat tracheal epithelium. Am J Respir Cell Mol Biol. 1993;9(4):361-70.

24. Clement CG, Evans SE, Evans CM, Hawke D, Kobayashi R, Reynolds PR, et al. Stimulation of lung innate immunity protects against lethal pneumococcal pneumonia in mice. Am J Respir Crit Care Med. 2008;177(12):1322-30.

25. Murray AB, Luz A. Acidophilic macrophage pneumonia in laboratory mice. Vet Pathol. 1990;27(4):274-81.

26. Guo L, Johnson RS, Schuh JC. Biochemical characterization of endogenously formed eosinophilic crystals in the lungs of mice. J Biol Chem. 2000;275(11):8032-7.

27. Johansson ME, Hansson GC. Preservation of mucus in histological sections, immunostaining of mucins in fixed tissue, and localization of bacteria with FISH. Methods Mol Biol. 2012;842:229-35.

28. Hogg JC. The pathology of asthma. APMIS. 1997;105(10):735-45.

29. Walter MJ, Kajiwara N, Karanja P, Castro M, Holtzman MJ. Interleukin 12 p40 production by barrier epithelial cells during airway inflammation. J Exp Med. 2001;193(3):33951. 30. Look DC, Walter MJ, Williamson MR, Pang L, You Y, Sreshta JN, et al. Effects of paramyxoviral infection on airway epithelial cell Foxj1 expression, ciliogenesis, and mucociliary function. Am J Pathol. 2001;159(6):2055-69.

31. Jakab GJ, Green GM. The effect of Sendai virus infection on bactericidal and transport mechanisms of the murine lung. J Clin Invest. 1972;51(8):1989-98. 
32. Evans CM, Williams OW, Tuvim MJ, Nigam R, Mixides GP, Blackburn MR, et al. Mucin is produced by clara cells in the proximal airways of antigen-challenged mice. Am $\mathrm{J}$ Respir Cell Mol Biol. 2004;31(4):382-94.

33. Nguyen LP, Omoluabi O, Parra S, Frieske JM, Clement C, Ammar-Aouchiche Z, et al. Chronic exposure to beta-blockers attenuates inflammation and mucin content in a murine asthma model. Am J Respir Cell Mol Biol. 2008;38(3):256-62.

34. Treutlein B, Brownfield DG, Wu AR, Neff NF, Mantalas GL, Espinoza FH, et al. Reconstructing lineage hierarchies of the distal lung epithelium using single-cell RNA-seq. Nature. 2014;509(7500):371-5.

35. Oczypok EA, Perkins TN, Oury TD. Alveolar Epithelial Cell-Derived Mediators: Potential Direct Regulators of Large Airway and Vascular Responses. Am J Respir Cell Mol Biol. 2017;56(6):694-9.

36. Tuvim MJ, Evans SE, Clement CG, Dickey BF, Gilbert BE. Augmented lung inflammation protects against influenza A pneumonia. PLoS ONE. 2009;4(1):e4176.

37. Evans SE, Scott BL, Clement CG, Larson DT, Kontoyiannis D, Lewis RE, et al.

Stimulated innate resistance of lung epithelium protects mice broadly against bacteria and fungi. Am J Respir Cell Mol Biol. 2010;42(1):40-50.

38. Djukanovic R, Harrison T, Johnston SL, Gabbay F, Wark P, Thomson NC, et al. The effect of inhaled IFN-beta on worsening of asthma symptoms caused by viral infections. A randomized trial. Am J Respir Crit Care Med. 2014;190(2):145-54.

39. Moreno-Vinasco L, Verbout NG, Fryer AD, Jacoby DB. Retinoic acid prevents virusinduced airway hyperreactivity and M2 receptor dysfunction via anti-inflammatory and antiviral effects. Am J Physiol Lung Cell Mol Physiol. 2009;297(2):L340-L6.

40. Pichery M, Mirey E, Mercier P, Lefrancais E, Dujardin A, Ortega N, et al. Endogenous IL-33 is highly expressed in mouse epithelial barrier tissues, lymphoid organs, brain, embryos, and inflamed tissues: in situ analysis using a novel Il-33-LacZ gene trap reporter strain. $\mathbf{J}$ Immunol. 2012;188(7):3488-95.

41. Klassen C, Karabinskaya A, Dejager L, Vettorazzi S, Van Moorleghem J, Luhder F, et al. Airway Epithelial Cells Are Crucial Targets of Glucocorticoids in a Mouse Model of Allergic Asthma. J Immunol. 2017;199(1):48-61.

42. Boucher RC. Muco-Obstructive Lung Diseases. N Engl J Med. 2019;380(20):1941-53.

43. Zhu Y, Ehre C, Abdullah LH, Sheehan JK, Roy M, Evans CM, et al. Munc13-2-/baseline secretion defect reveals source of oligomeric mucins in mouse airways. J Physiol. 2008;586(7):1977-92.

44. Jackson DJ, Makrinioti H, Rana BM, Shamji BW, Trujillo-Torralbo MB, Footitt J, et al. IL-33-dependent type 2 inflammation during rhinovirus-induced asthma exacerbations in vivo. Am J Respir Crit Care Med. 2014;190(12):1373-82.

45. Mallia P, Message SD, Gielen V, Contoli M, Gray K, Kebadze T, et al. Experimental rhinovirus infection as a human model of chronic obstructive pulmonary disease exacerbation. Am J Respir Crit Care Med. 2011;183(6):734-42.

46. Adura PT, Reed E, Macintyre J, Del Rosario A, Roberts J, Pestridge R, et al. Experimental rhinovirus 16 infection in moderate asthmatics on inhaled corticosteroids. Eur Respir J. 2014;43(4):1186-9.

47. Sheshadri A, Shah DP, Godoy M, Erasmus JJ, Song J, Li L, et al. Progression of the Radiologic Severity Index predicts mortality in patients with parainfluenza virus-associated lower respiratory infections. PLoS One. 2018;13(5):e0197418. 
48. Chemaly RF, Shah DP, Boeckh MJ. Management of respiratory viral infections in hematopoietic cell transplant recipients and patients with hematologic malignancies. Clin Infect Dis. 2014;59 Suppl 5:S344-51.

49. Schmittgen TD, Livak KJ. Analyzing real-time PCR data by the comparative C(T) method. Nat Protoc. 2008;3(6):1101-8.

50. Tuvim MJ, Mospan AR, Burns KA, Chua M, Mohler PJ, Melicoff E, et al. Synaptotagmin 2 couples mucin granule exocytosis to $\mathrm{Ca} 2+$ signaling from endoplasmic reticulum. J Biol Chem. 2009;284(15):9781-7.

51. Piccotti L, Dickey BF, Evans CM. Assessment of intracellular mucin content in vivo. Methods Mol Biol. 2012;842:279-95.

52. Evans CM, Raclawska DS, Ttofali F, Liptzin DR, Fletcher AA, Harper DN, et al. The polymeric mucin Muc5ac is required for allergic airway hyperreactivity. Nat Commun. 2015;6:6281.

53. Schindelin J, Arganda-Carreras I, Frise E, Kaynig V, Longair M, Pietzsch T, et al. Fiji: an open-source platform for biological-image analysis. Nat Methods. 2012;9(7):676-82.

54. Ren B, Azzegagh Z, Jaramillo AM, Zhu Y, Pardo-Saganta A, Bagirzadeh R, et al. SNAP23 is selectively expressed in airway secretory cells and mediates baseline and stimulated mucin secretion. Biosci Rep. 2015;35(3).

55. Ehre C, Worthington EN, Liesman RM, Grubb BR, Barbier D, O'Neal WK, et al. Overexpressing mouse model demonstrates the protective role of Muc5ac in the lungs. Proc Natl Acad Sci U S A. 2012;109(41):16528-33. 


\section{Figures:}
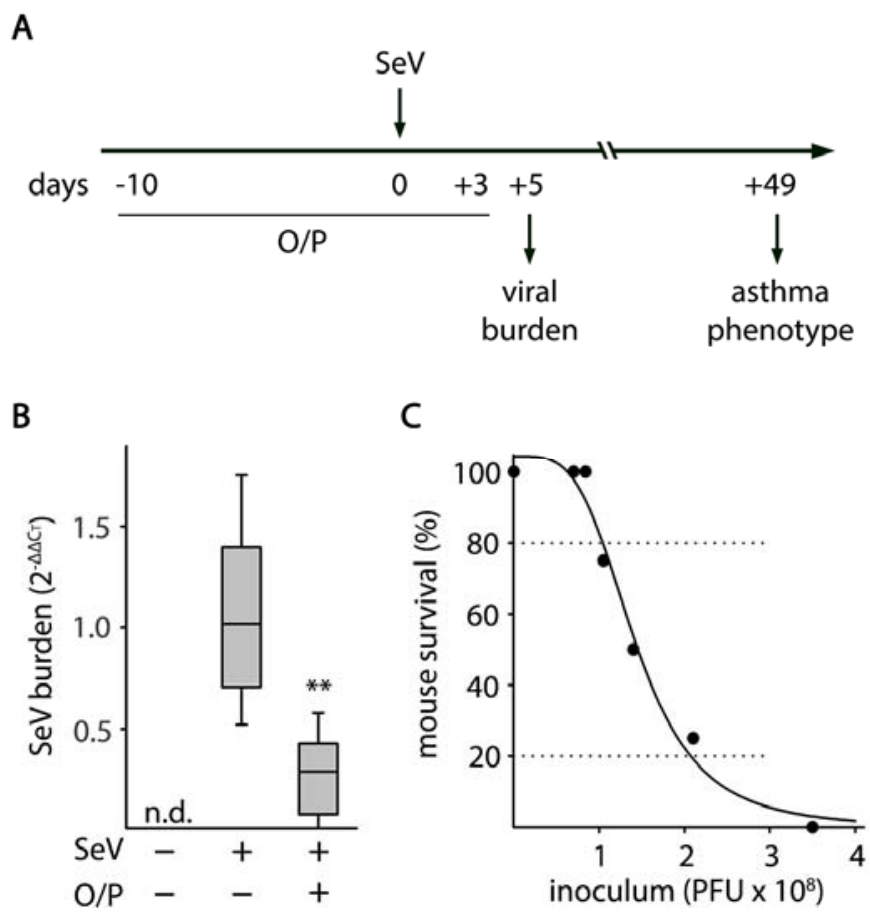

Fig. 1. Experimental paradigm, effect of $\mathrm{O} / \mathrm{P}$ treatment on lung $\mathrm{SeV}$ burden, and correlation between SeV burden and mouse survival. (A) Illustration of the experimental paradigm with $\mathrm{O} / \mathrm{P}$ administered by aerosol a few days before or after $\mathrm{SeV}$ challenge, lung $\mathrm{SeV}$ burden assessed 5 days after challenge, and development of an asthma phenotype assessed 49 days after challenge. (B) Lung SeV burden measured by qRT-PCR 5 days after mice were challenged with $\mathrm{SeV}$, with or without treatment one day earlier with O/P. (Boxes show median and interquartile range, whiskers show $10^{\text {th }}$ and $90^{\text {th }}$ percentiles; $* * P<0.01$ for $\left[\mathrm{SeV}^{+}, \mathrm{O} / \mathrm{P}^{+}\right] v s$ $\left[\mathrm{SeV}^{+}, \mathrm{O} / \mathrm{P}^{-}\right]$by Student's $t$-test; $\mathrm{N}=24$ mice/group pooled from 4 experiments.) (C) Various $\mathrm{SeV}$ inocula were administered to determine the correlation between lung $\mathrm{SeV}$ burden and mouse survival. ( $\mathrm{N}=4 \mathrm{mice} / g r o u p$ in a representative experiment performed 5 times). 
A

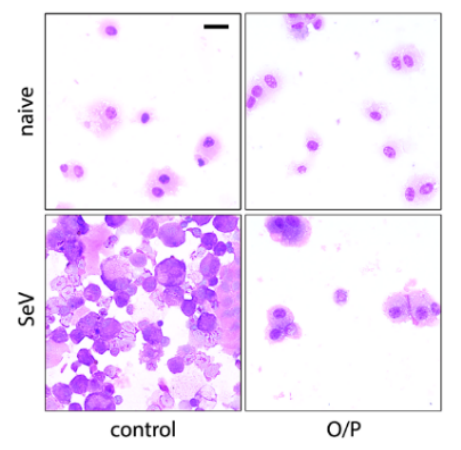

C

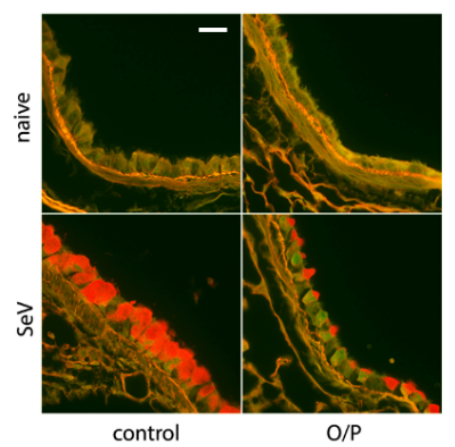

E

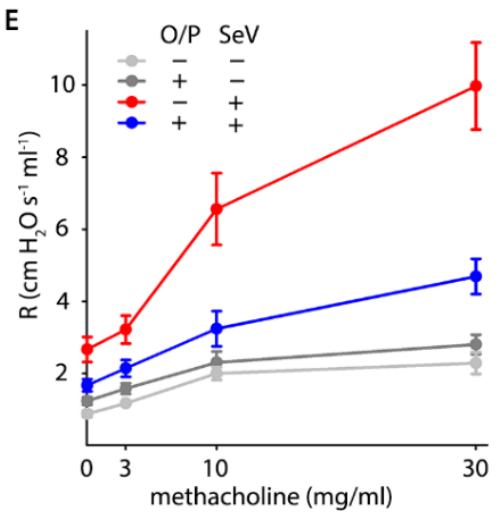

B

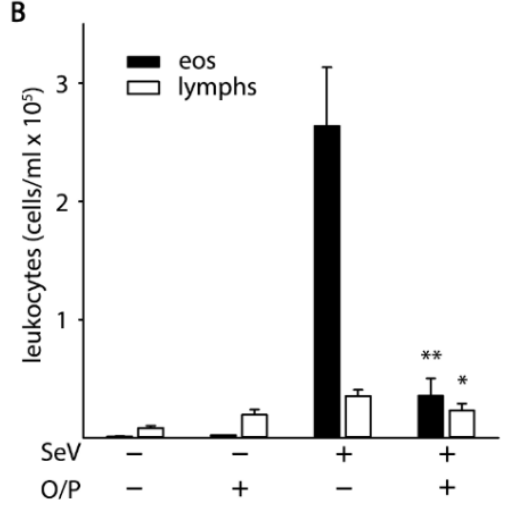

D

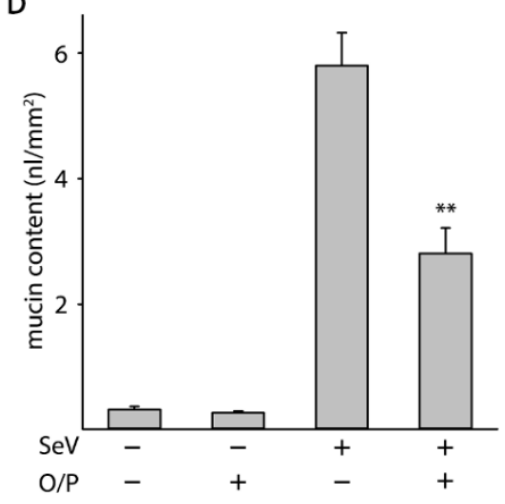

$\mathrm{F}$

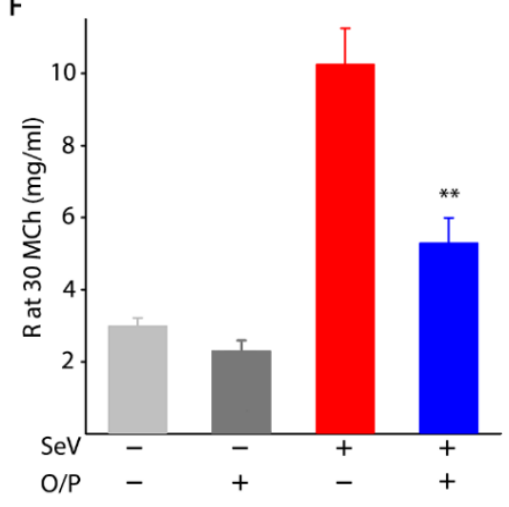

Fig. 2. Effects of $\mathrm{O} / \mathrm{P}$ treatment on asthma phenotype 49 days after $\mathrm{SeV}$ challenge. (A) Leukocytes obtained by lung lavage were pelleted onto glass slides by centrifugation and stained with Wright-Giemsa. Scale bar $=20 \mu \mathrm{m}$. (B) Eosinophils and lymphocytes in lung lavage fluid were enumerated. (Bars show mean $\pm \mathrm{SEM} ; * P<0.05$ and $* * P<0.01$ for $\left[\mathrm{SeV}^{+}, \mathrm{O} / \mathrm{P}^{+}\right] v s$ $\left[\mathrm{SeV}^{+}, \mathrm{O} / \mathrm{P}^{-}\right]$by Student's $t$-test; $\mathrm{N}=21$ mice/group pooled from 3 experiments.) (C) Airway epithelium stained with PAFS to demonstrate intracellular mucin in red. Scale bar $=20 \mu \mathrm{m}$. (D) Quantification of intracellular mucin content by image analysis of airway as in (C). (Bars and $P$ values as in (B); $\mathrm{N}=22-25$ mice/group pooled from 5 experiments.). (E) Dose-response relationship between the concentration of aerosolized methacholine and total respiratory resistance measured by forced oscillation. (Points show mean \pm SEM; $N=9-14$ mice per group pooled from 3 experiments.) (F) Plot of total respiratory resistance at $30 \mathrm{mg} / \mathrm{ml}$ methacholine (MCh) using data from E. (Bars and $P$ values as in (B)). 

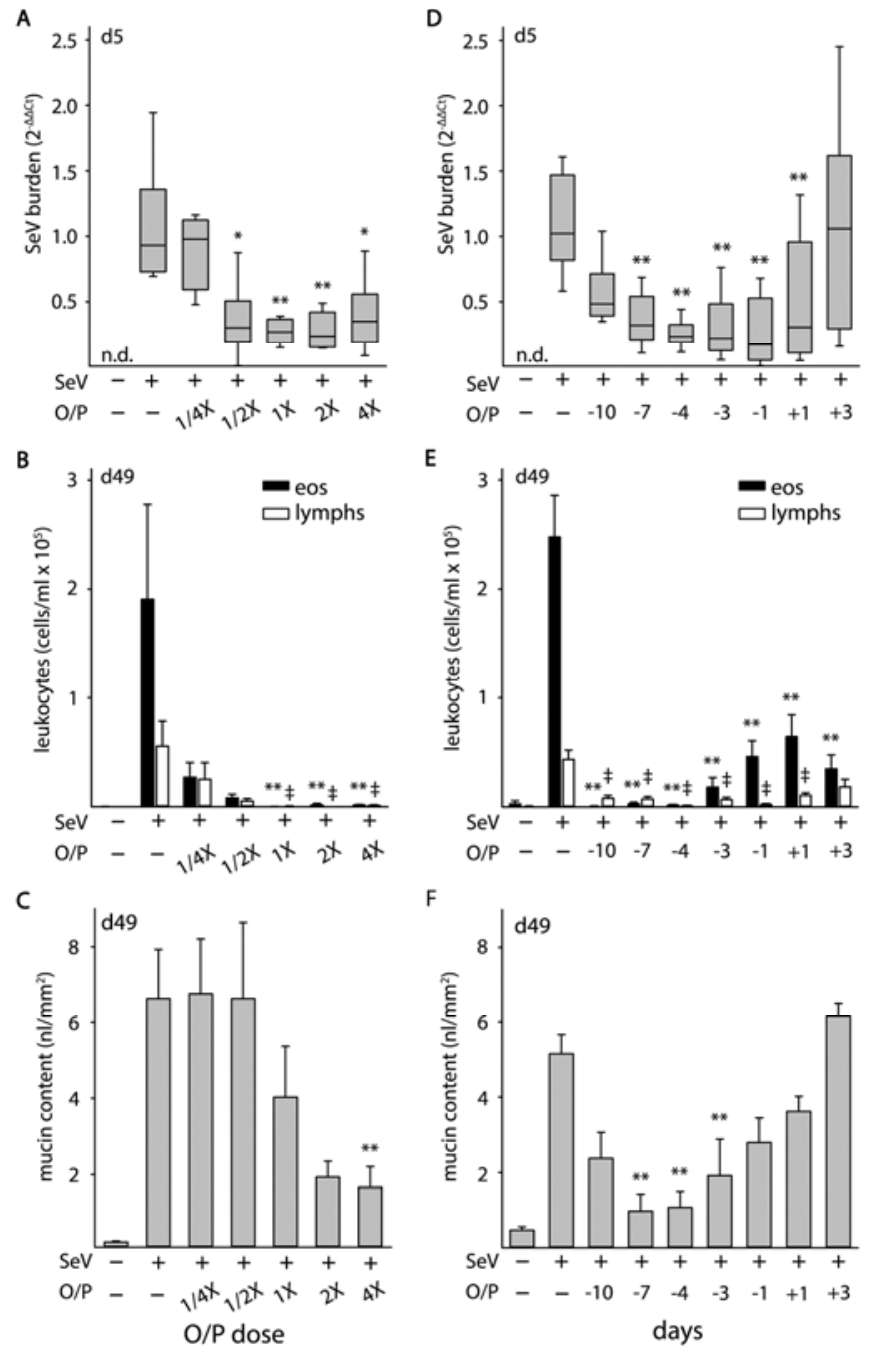

Fig. 3. Dose and temporal response relationships between $\mathrm{O} / \mathrm{P}$ treatment and acute lung $\mathrm{SeV}$ burden and late asthma phenotypes. (A) Relationship between $\mathrm{O} / \mathrm{P}$ dose and lung $\mathrm{SeV}$ burden 5 days after $\mathrm{SeV}$ challenge. (Boxes show median and interquartile range, whiskers show $10^{\text {th }}$ and $90^{\text {th }}$ percentiles; $* P<0.05$ and $* * P<0.01$ for ANOVA on ranks with Dunn's test for multiple comparisons against $\left[\mathrm{SeV}^{+}, \mathrm{O} / \mathrm{P}^{-}\right]$control; $\mathrm{N}=5-6$ mice/group in a single experiment; n.d. $=$ not detectable.) $(\mathbf{B})$ Relationship between $\mathrm{O} / \mathrm{P}$ dose and lung lavage eosinophil and lymphocyte numbers 49 days after $\mathrm{SeV}$ challenge. (Bars show mean $\pm \mathrm{SEM} ; * * P<0.01$ as in (A), $\square P<0.01$ for comparisons on lymphocytes; $\mathrm{N}=5$ mice/group in a single experiment.) (C) Relationship between $\mathrm{O} / \mathrm{P}$ dose and intracellular mucin content 49 days after $\mathrm{SeV}$ challenge. (Bars show mean $\pm \mathrm{SEM} ;{ }^{* *} P<0.01$ as in (A); N=6-7 in a single experiment.) (D) Relationship of the interval in days between $\mathrm{O} / \mathrm{P}$ treatment and $\mathrm{SeV}$ challenge in $\mathrm{SeV}$ lung burden 5 days after challenge. (Box plot and $P$ values as in (A); N=25-39 mice/group pooled from 7 experiments.) (E) Relationship of the interval between $\mathrm{O} / \mathrm{P}$ treatment and $\mathrm{SeV}$ challenge in lung lavage eosinophil and lymphocyte numbers 49 days after challenge. (Bars and $P$ values as in (B); N=25-29 mice/group pooled from 6 experiments). (F) Relationship of the interval between $\mathrm{O} / \mathrm{P}$ treatment and $\mathrm{SeV}$ challenge in intracellular mucin content 49 days after challenge. (Bars and $P$ values as in $(\mathrm{C})$; $\mathrm{N}=6-12$ mice/group pooled from 3 experiments.) 
A

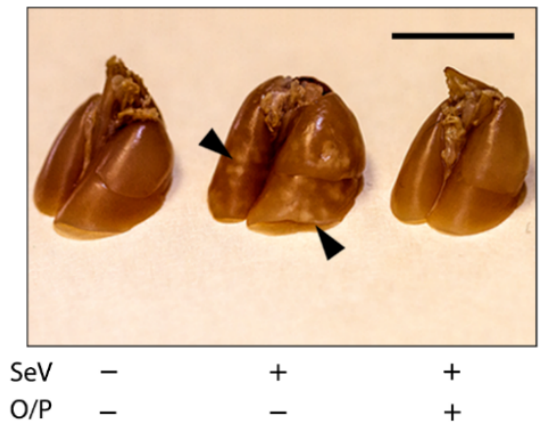

D

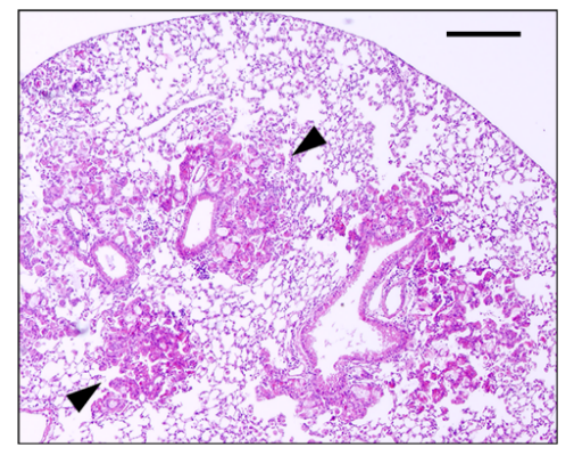

B

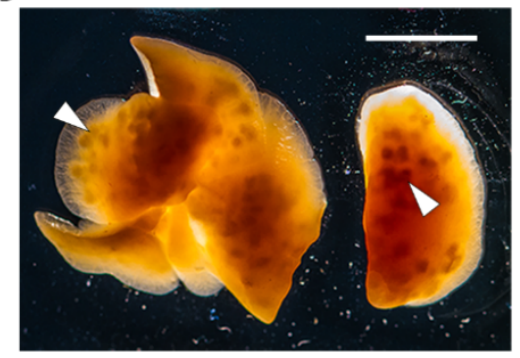

E

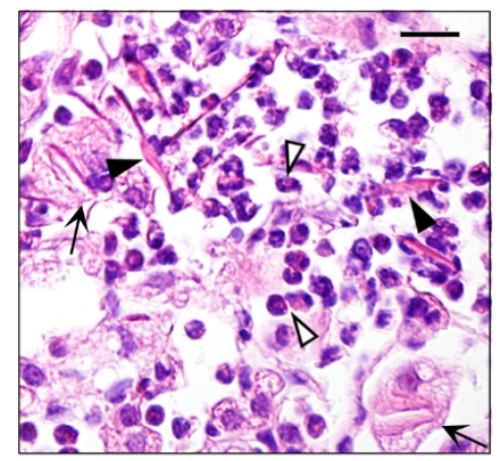

C

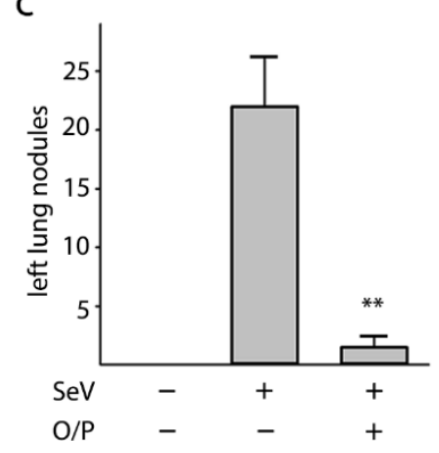

$\mathrm{F}$

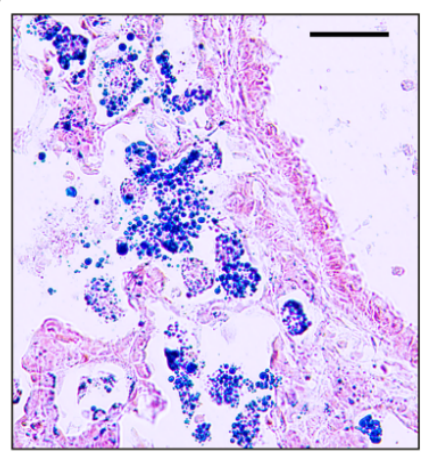

G

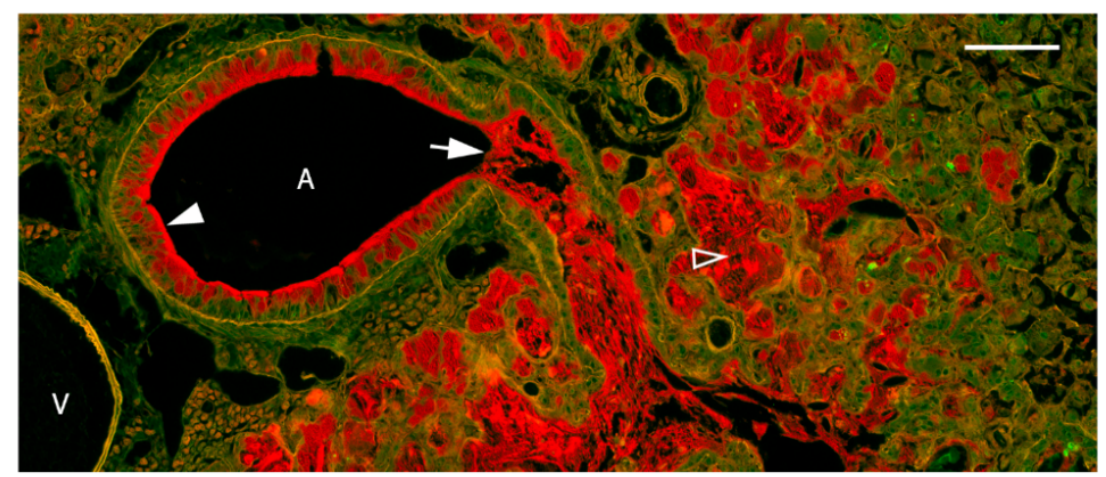

$\mathrm{H}$

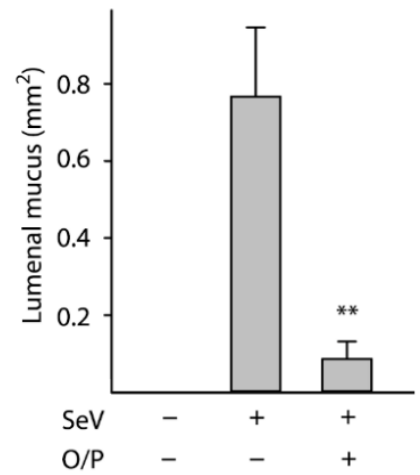

I

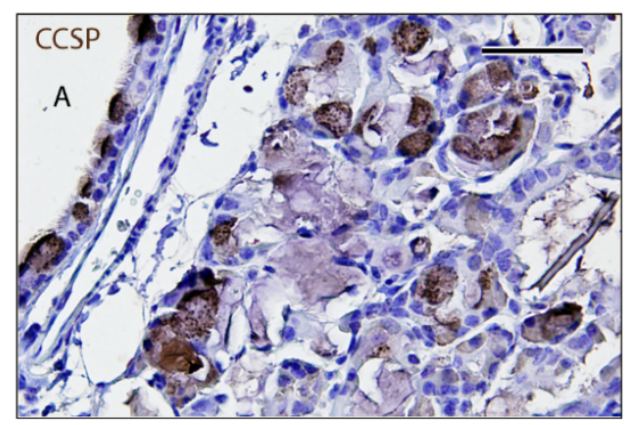

$J$

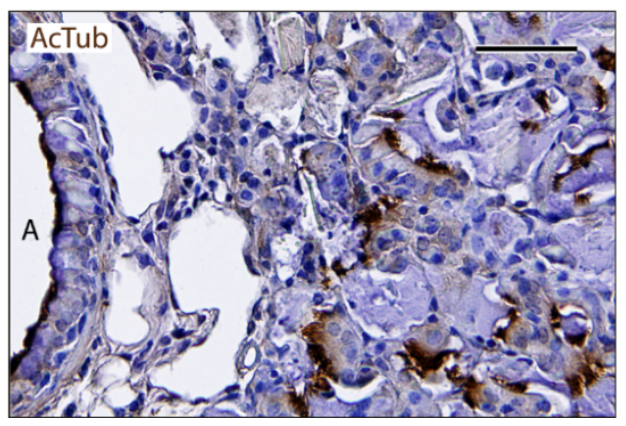

$\mathrm{K}$

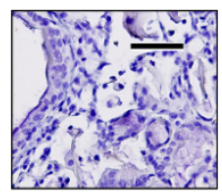

$\mathrm{L}$

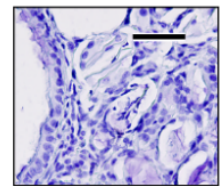

Fig. 4. Airway mucus occlusion, acidophilic pneumonitis, and alveolar bronchiolization after $\mathrm{SeV}$ infection. Legend on next page. 
Fig. 4. Airway mucus occlusion, acidophilic pneumonitis, and alveolar bronchiolization 49 days after SeV infection. (A) The lungs of mice treated or not with $\mathrm{O} / \mathrm{P}$, then challenged or not with $\mathrm{SeV}$ one day later, then sacrificed 49 days later with lungs inflated with $10 \%$ formalin to 20 $\mathrm{cm}_{2} \mathrm{O}$ pressure. Arrowheads points to nodules on the lung surface. Scale bar $=1 \mathrm{~cm}$. (B) Transilluminated lungs from a mouse challenged with $\mathrm{SeV}$ but not treated with $\mathrm{O} / \mathrm{P}$, as in (A). Arrowheads point to nodules in the lung interior. Scale bar $=1 \mathrm{~cm}$. (C) Enumeration of nodules in the left lungs of mice treated with $\mathrm{O} / \mathrm{P}$ and challenged with $\mathrm{SeV}$ as in (A). (Bars indicate mean $\pm \mathrm{SEM}$; ** $P<0.01$ for $\left[\mathrm{SeV}^{+}, \mathrm{O} / \mathrm{P}^{+}\right]$vs $\left[\mathrm{SeV}^{+}, \mathrm{O} / \mathrm{P}^{-}\right]$by Student's $t$-test; $\mathrm{N}=4-5$ in a single experiment.) (D) Section of the lung of a mouse challenged with $\mathrm{SeV}$ but not treated with O/P, stained with H\&E. Arrowheads point to nodules. Scale bar $=0.5 \mathrm{~mm}$. (E) High magnification image of a nodule from a mouse as in (D), with closed arrowheads pointing to Charcot-Leyden crystals, open arrowheads pointing to eosinophils, and arrows pointing to foamy macrophages. Scale bar $=30 \mu \mathrm{m}$. (F) Image of a nodule from a mouse as in (D), but with lungs frozen and stained with Sudan black to show lipids within macrophages. Scale bar $=50 \mu \mathrm{m}$. (G) Section of the lung of a mouse challenged with $\mathrm{SeV}$ but not treated with $\mathrm{O} / \mathrm{P}$, fixed by immersion in methacarn and stained with PAFS. Closed arrowhead points to abundant intracellular mucin, arrow points to lumenal mucus occlusion, open arrowhead points to mucus in the alveolar region. $\mathrm{A}=$ airway, $\mathrm{V}=$ vessel. Scale $\mathrm{bar}=100 \mu \mathrm{m}$. $(\mathbf{H})$ The area of lumenal mucus of mice treated or not with $\mathrm{O} / \mathrm{P}$, then challenged or not with $\mathrm{SeV}$, then fixed and stained as in (G), with left lungs sectioned at fixed intervals using a precision cutting tool. (Bars indicate mean $\pm \mathrm{SEM}$; $* * P<0.01$ for $\left[\mathrm{SeV}^{+}, \mathrm{O} / \mathrm{P}^{+}\right]$vs $\left[\mathrm{SeV}^{+}, \mathrm{O} / \mathrm{P}^{-}\right]$by Mann-Whitney $U$ test; $\mathrm{N}=13-15$ mice/group in a single experiment.) (I-L) Alveolar region of a mouse challenged with $\mathrm{SeV}$ but not treated with O/P, stained with antibodies against (I) CCSP or (J) acetylated tubulin (both brown), and counterstained with H\&E (blue). A = airway lumens. Primary antibodies against (K) CCSP or (L) acetylated tubulin were omitted to assess the specificity of antibody staining. Scale bar in all 4 images $=50 \mu \mathrm{m}$. 


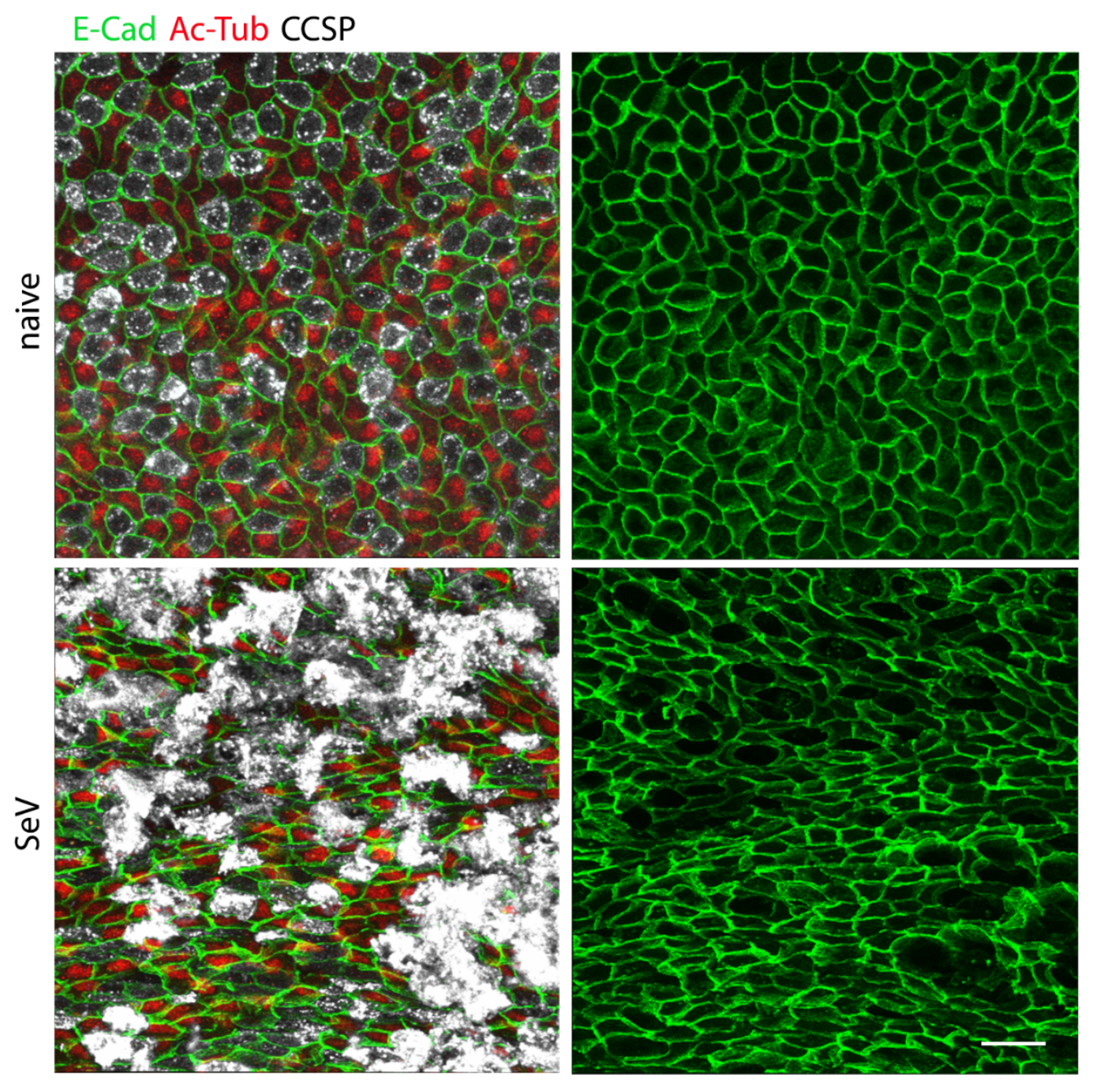

Fig. 5. SeV infection alters the normal airway epithelial mosaic. Whole mount immunofluorescence images of proximal portions of the axial bronchi of mice infected or not with SeV 5 weeks earlier. Images on the left show staining for E-cadherin (E-Cad, green) to outline cell borders, acetylated tubulin (Ac-Tub, red) to identify ciliated cells, and club cell secretory protein (CCSP, white) to identify secretory cells. Images on the right only show staining for E-cadherin to better illustrate changes in cell shape and pattern. Scale bar $=20 \mu \mathrm{m}$. 
A

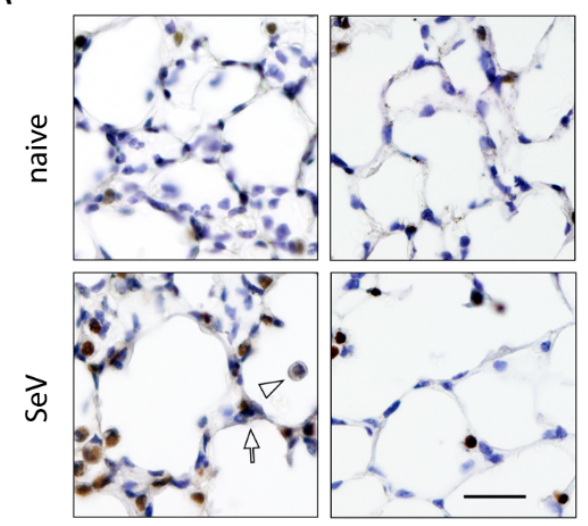

control

C

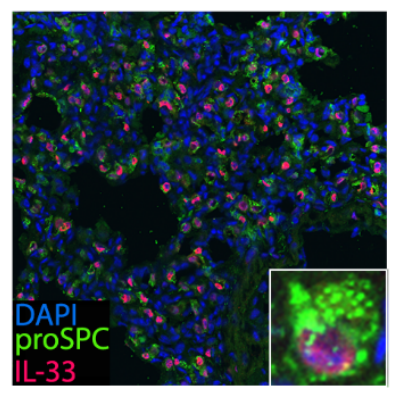

B

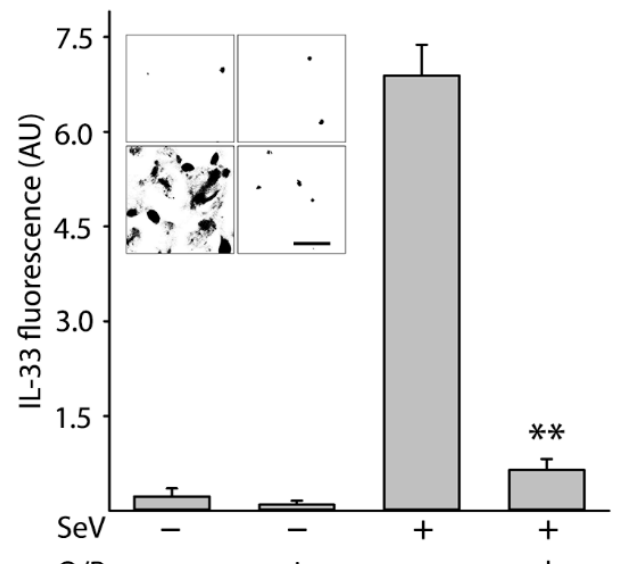

$\mathrm{O} / \mathrm{P} \quad-\quad+\quad-\quad+$

$\mathrm{E}$
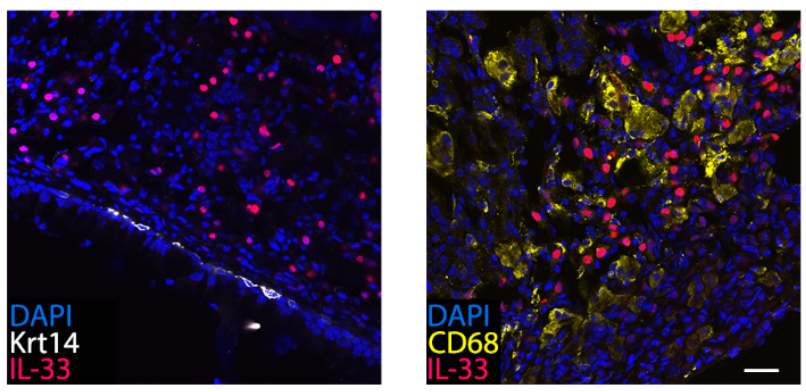

Fig. 6. Persistent IL-33 expression after SeV challenge. (A) Images of the lungs of mice treated or not with $\mathrm{O} / \mathrm{P}$, then challenged or not with $\mathrm{SeV}$ one day later, then sacrificed 49 days later. Brown color is immunohistochemical staining for IL-33. Arrow points to an intensely stained alveolar T2 cell, arrowhead points to a faintly stained macrophage. Scale bar $=100 \mu \mathrm{m}$. (B) Same groups as in (A), but with fluorescence staining for IL-33. Inset shows masking for staining greater than background. Scale bar $=100 \mu \mathrm{m}$. (Bars indicate mean $\pm \mathrm{SEM} ; * * P<0.01$ for $\left[\mathrm{SeV}^{+}, \mathrm{O} / \mathrm{P}^{+}\right]$vs $\left[\mathrm{SeV}^{+}, \mathrm{O} / \mathrm{P}^{-}\right]$by Student's $t$-test; $\mathrm{N}=3$ mice/group in a single experiment, with 3 fields examined per mouse.) (C) Fluorescence staining for proSPC to identify alveolar T2 cells (green), IL-33 (red), and DAPI to identify nuclei (blue). Inset shows IL-33 expression in a T2 cell. (D) Fluorescence staining for cytokeratin 14 (Krt14) to identify airway basal cells (white), and IL-33 and DAPI as in (C), shows no apparent expression of IL-33 in basal cells. (E) Fluorescence staining for CD68 to identify macrophages (yellow), and IL-33 and DAPI as in (C), shows no apparent expression of IL-33 in macrophages. Scale bar for $(C, D, E)=200 \mu \mathrm{m}$, and for inset in $(\mathrm{C})=30 \mu \mathrm{m}$. 
A

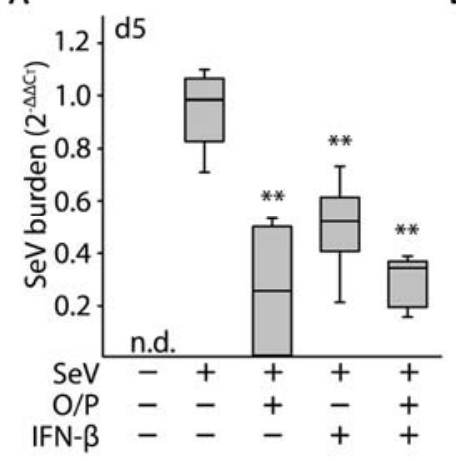

B

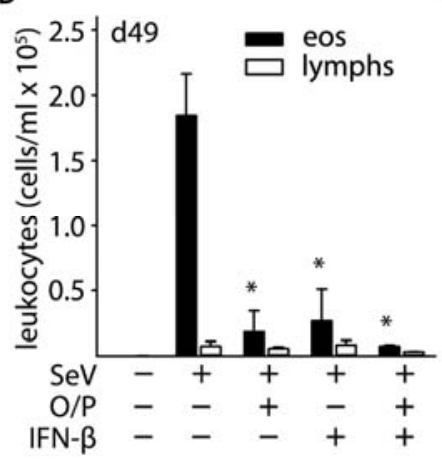

C

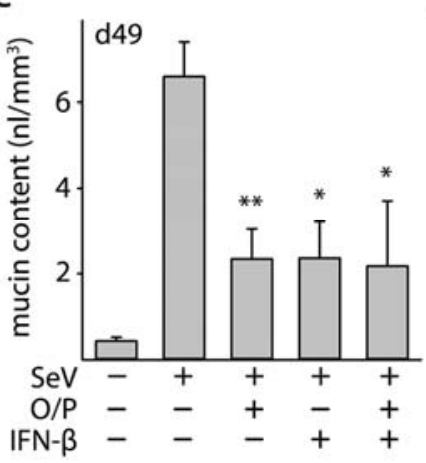

D

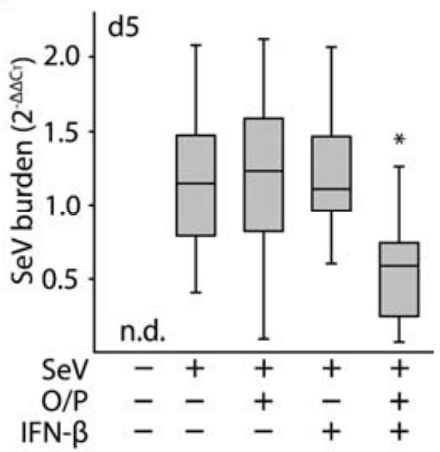

Fig. 7. Effects of multiple O/P doses on tachyphylaxis and efficacy. (A) Experimental paradigm illustrating the timing of $\mathrm{O} / \mathrm{P}$ doses for each experimental group in black triangles in relation to the $\mathrm{SeV}$ challenge given on day 0 . (B) Lung SeV burden by qRT-PCR 5 days after mice were challenged with $\mathrm{SeV}$, with or without pretreatment with $\mathrm{O} / \mathrm{P}$ as outlined in $(\mathrm{A})$. (Boxes show median and interquartile range, whiskers show $10^{\text {th }}$ and $90^{\text {th }}$ percentiles; $* * P<0.01$ for analysis by ANOVA on ranks with Dunn's test for multiple comparisons against $\left[\mathrm{SeV}^{+}, \mathrm{O} / \mathrm{P}^{-}\right]$ control; N=4-7 mice/group in a single experiment; n.d. = not detectable.) (C) Lung SeV burden by RT-qPCR 5 days after mice were challenged with $\mathrm{SeV}$, with or without treatment with $\mathrm{O} / \mathrm{P}$ one day before challenge $(-1)$, one day after challenge $(+1)$, or both $(-/+1)$. (Box plot and $P$ values as in (B); bar and labeled $P$ values for single comparison between $\left[\mathrm{SeV}^{+}, \mathrm{O} / \mathrm{P}^{-1}\right] v s$ $\left[\mathrm{SeV}^{+}, \mathrm{O} / \mathrm{P}^{-/+1}\right]$ by Student's $t$-test; $\mathrm{N}=14-25$ mice/group pooled from 3 experiments.) (D) Eosinophils and lymphocytes in lung lavage fluid were enumerated 49 days after SeV challenge, with or without treatment with $\mathrm{O} / \mathrm{P}$ as in $(\mathrm{C})$. (Bars show mean $\pm \mathrm{SEM} ; * P<0.05$ and $* * P<0.01$ as in (B), ${ }^{\dagger} P<0.05$ and ${ }^{\square} P<0.01$ for comparisons on lymphocytes; bar and labeled $P$ values as in (C); N=8-11 mice/group pooled from 2 experiments.) (E) Quantification of intracellular mucin content of airway epithelium 49 days after $\mathrm{SeV}$ challenge, with or without treatment with $\mathrm{O} / \mathrm{P}$ as in (C). (Bars and $P$ values as in (C); $\mathrm{N}=8-11$ mice/group pooled from 2 experiments.) 
A

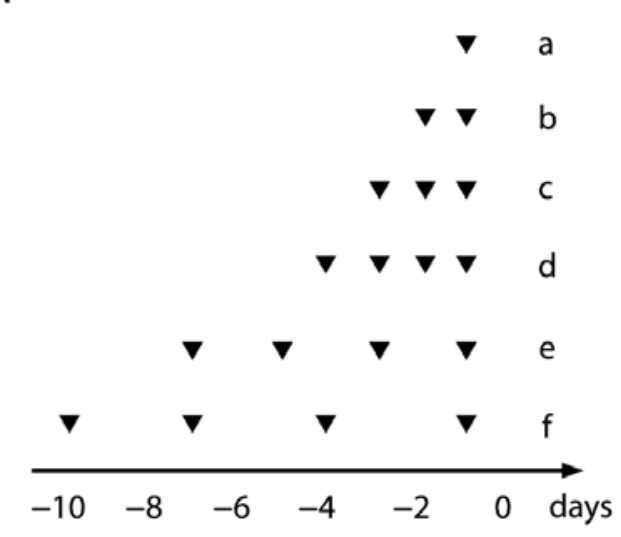

B

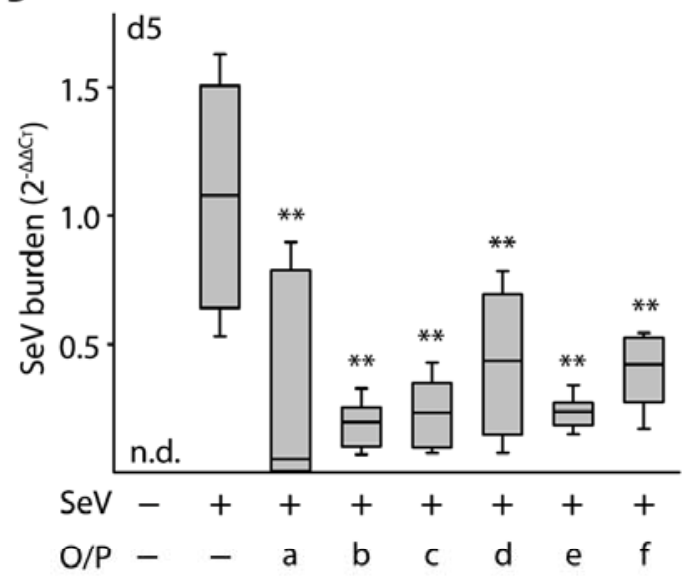

C

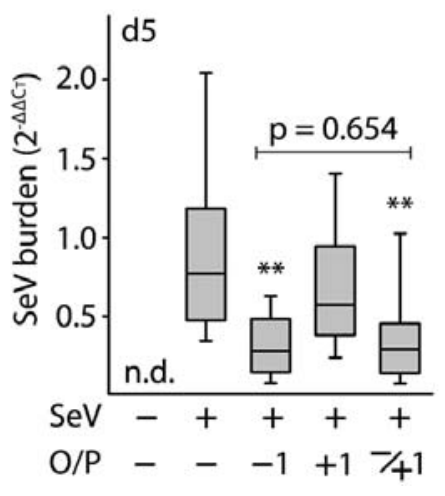

D

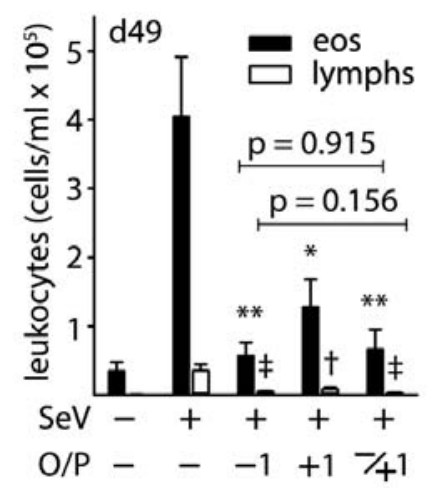

$\mathrm{E}$

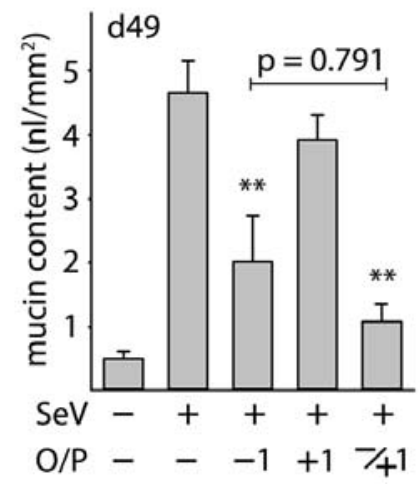

Fig. 8. Comparison of the effects of $\mathrm{O} / \mathrm{P}$ and IFN- $\beta$ on acute lung SeV burden and late asthma phenotypes. (A) Lung SeV burden by qRT-PCR 5 days after mice were challenged with $\mathrm{SeV}$, with or without pretreatment one day earlier with $\mathrm{O} / \mathrm{P}$, IFN- $\beta$, or both. (Boxes show median and interquartile range, whiskers show $10^{\text {th }}$ and $90^{\text {th }}$ percentiles; $* P<0.05$ and $* * P<0.01$ for $\left[\mathrm{SeV}^{+}\right.$, drug $\left.{ }^{+}\right]$vs $\left[\mathrm{SeV}^{+}\right.$, $\left.\mathrm{drug}^{-}\right]$, with $P>0.05$ for all other possible pairwise comparisons by oneway ANOVA with Holm-Sidak's test for multiple comparisons; N=4-6 mice/group in a single experiment; n.d. = not detectable.) (B) Eosinophils and lymphocytes in lung lavage fluid were enumerated 49 days after $\mathrm{SeV}$ challenge as in (A). (Bars show mean $\pm \mathrm{SEM} ; P$ values as in (A); $\mathrm{N}=4-6$ mice/group in a single experiment.) (C) Quantification of intracellular mucin content of airway epithelium 49 days after $\mathrm{SeV}$ challenge as in (A). (Bars and $P$ values are as in (A); N=3-4 in a single experiment). (D) Lung SeV burden by RT-qPCR 5 days after mice were challenged with a high dose of $\mathrm{SeV}\left(2.5 \times \mathrm{LD}_{50}\right)$, with or without pretreatment one day earlier with $\mathrm{O} / \mathrm{P}$, IFN- $\beta$, or both. (Boxes show median and interquartile range, whiskers show $10^{\text {th }}$ and $90^{\text {th }}$ percentiles, n.d.=not detectable; $* P<0.05$ for both drugs together $v s$ either drug alone by one-way ANOVA with Holm-Sidak's test for multiple comparisons; $N=3$ for the uninfected group, 10 for all other groups in a single experiment.) 